\title{
PERSOC: A Unified Framework for Understanding the Dynamic Interplay of Personality and Social Relationships
}

\author{
MITJA D. BACK ${ }^{1 *}$, ANNA BAUMERT ${ }^{2}$, JAAP J.A. DENISSEN ${ }^{3}$, FREDA-MARIE HARTUNG ${ }^{4}$, LARS PENKE ${ }^{5}$, \\ STEFAN C. SCHMUKLE ${ }^{6}$, FELIX D. SCHÖNBRODT ${ }^{7}$, MICHELA SCHRÖDER-ABÉ $^{8}$, MANJA VOLLMANN ${ }^{4}$, \\ JENNY WAGNER ${ }^{9}$ and CORNELIA WRZUS ${ }^{10}$ \\ ${ }^{1}$ Department of Psychology, Johannes Gutenberg University Mainz, Mainz, Germany \\ ${ }^{2}$ Department of Psychology, University of Koblenz-Landau, Germany \\ ${ }^{3}$ Institute of Psychology, Humboldt-University Berlin, Germany \\ ${ }^{4}$ Department of Psychology, University of Konstanz, Germany \\ ${ }^{5}$ Department of Psychology and Centre for Cognitive Ageing and Cognitive Epidemiology, University of Edinburgh, UK \\ ${ }^{6}$ Department of Psychology, Westfälische Wilhelms-University Münster, Germany \\ ${ }^{7}$ Department of Psychology, Ludwig-Maximilians-University München, Germany \\ ${ }^{8}$ Department of Psychology, Chemnitz University of Technology, Germany \\ 9 Institute of Psychology, Humboldt-University Berlin, Germany \\ ${ }^{10}$ Department of Psychology, Max Planck Institute for Human Development Berlin, Germany
}

\begin{abstract}
The interplay of personality and social relationships is as fascinating as it is complex and it pertains to a wide array of largely separate research domains. Here, we present an integrative and unified framework for analysing the complex dynamics of personality and social relationships (PERSOC). Basic principles and general processes on the individual and dyadic level are outlined to show how personality and social relationships influence each other and develop over time. PERSOC stresses the importance of social behaviours and interpersonal perceptions as mediating processes organized in social interaction units. The framework can be applied to diverse social relationships such as first encounters, short-term acquaintances, friendships, relationships between working group members, educational or therapeutic settings, romantic relationships and family relationships. It has important consequences for how we conceptualize, understand, and investigate personality and social relationships. Copyright (C) 2011 John Wiley \& Sons, Ltd.
\end{abstract}

Key words: personality; social relationships; actual behaviour; interpersonal perception; social relations model; mediating processes; development

Human beings are characterized as social animals possessing a fundamental need to belong to others (Baumeister \& Leary, 1995). Most of our behaviours, thoughts and emotions are social, meaning that they are directly or indirectly related to other people. Consequently, personality (how people are) is inseparably interwoven with social relationships (who people are with). First, a relevant part of personality is characterized by interindividual differences in how people act towards others and how they think and feel about others and about themselves in relation to others (James, 1890/ 1981). Personality would probably have less relevance if there were no social relationships (cf. Penke, Denissen, \& Miller, 2007, p. 567). Second, most important social actions, thoughts and feelings are partly determined by personality characteristics of the people involved. Social relationships would not be such a challenging part of our lives if all people were equal in how they act, think and feel. Third, social interactions feed back into the development of personality.

*Correspondence to: Mitja D. Back, Department of Psychology, Johannes Gutenberg-University Mainz, 55099 Mainz, Germany.

E-mail: back@uni-mainz.de
How others react towards us and how we feel and think about others has the potential to influence who we become (e.g. Denissen, Schönbrodt, van Zalk, Meeus, \& van Aken, 2011; Neyer \& Lehnart, 2007).

Despite personality and social relationships being intrinsically connected, social psychological research has long neglected the role of personality in determining social phenomena. Similarly, personality research has long been reluctant to study social real-life phenomena (see Funder, 2001, 2009). Fortunately, this situation has begun to change. More and more researchers have supported an interdisciplinary approach to personality and social relationships (Baumeister, 1999; Vohs \& Finkel, 2006; Vollrath, Krahé, \& Hampson, 2004; Wood, Tesser \& Holmes, 2008) and a growing number of social psychologists and personality researchers have called for a stronger focus on actual social behaviour (Back \& Egloff, 2009; Baumeister, Vohs, \& Funder, 2007; Furr, 2009; Penke, 2009). Integrative approaches have been applied in diverse fields such as interpersonal perceptions at zero acquaintance (e.g. Back, Stopfer, et al., 2010; Borkenau \& Liebler, 1992; Hartung \& Renner, 2011), peer-relationships (Asendorpf \& Wilpers, 
1998; Selfhout, Burk, Denissen, Branje, van Aken, \& Meeus, 2010), personality development (Asendorpf \& van Aken, 2003; Neyer \& Lehnart, 2007), romantic relationships (Donnellan, Larsen-Rife, \& Conger, 2005; Simpson, Collins, Tran, \& Haydon, 2007) or family ties (Branje, van Lieshout, \& van Aken, 2005; Denissen, van Aken, \& Dubas, 2009).

Although all of these approaches describe the interplay of personality and social phenomena, there is still a lack of cross-talk between and within subdisciplines (cf. Cooper, 2002): For each relationship type, personality domain, or level of acquaintance, separate concepts and labels are applied. Here, we present a unified framework for studying the complex dynamics between personality and social relationships. We call this framework PERSOC as it aims to conceptualize the interplay of PERsonality and SOCial relationships thereby providing conceptual guidelines as well as a common glossary for research on personality and social relationships in general.

A number of existing theoretical frameworks provide important specific insights regarding the interplay of personality and social relationships. PERSOC is based on the assumption that these different insights are not exclusive and that a unified framework of the personality-social relationships interplay needs to account for all of them. PERSOC integrates and systematically organizes key concepts, namely the expression of stable personality dispositions (e.g. Funder, 1991; five factor theory: McCrae and Costa (2008); theory of personality levels: McAdams \& Pals, 2006), the nature, development and influence of reputations ((neo-)socioanalytic theory: Hogan \& Roberts, 2000; Roberts \& Wood, 2006; also see: Hofstee, 1994; Vazire, 2010), the function of relationship qualities (Brown \& Brown, 2006; Fiske, 1992; Neyer, Wrzus, Wagner, \& Lang, in press), transactional personality development (identity negotiation theory: Swann \& Bosson, 2008; social investment theory: Roberts, Wood, \& Smith, 2005; also see: Caspi, 1998; Neyer \& Lehnart, 2007; Srivastava, John, Gosling, \& Potter, 2003), stages of relationship development (Altman \& Taylor, 1973; Levinger, 1994) and interpersonal interaction processes and components (lens models: Brunswik, 1956; Funder, 1999; social relations model: Back \& Kenny, 2010; Kenny, 1994).

PERSOC is the first attempt to integrate these key concepts of the personality-social relationship interplay into a coherent unified framework. Moreover, unlike previous models, PERSOC takes a closer look at the dynamic longitudinal interaction processes underlying the personality-social relationship interplay. It stresses the importance of social behaviours and interpersonal perceptions as mediating social interaction processes. This is crucial as the development and mutual influence of personality and social relationships cannot be understood without a detailed knowledge about the mediating social interaction processes.

It is important to note that PERSOC should not be considered as a theory of personality and social relationships because it does not specify which exact variables and processes account for their interplay given a specified relationship type and acquaintance level. Instead, it is thought as a general framework that describes and system- atically outlines basic groups of variables and processes. The framework can be applied different kinds of social relationships (everyday, work, pedagogical/educational, therapeutic, friend, family and romantic) at any stage of acquaintance (zero to long-term acquaintance). PERSOC thus functions as a general heuristic of how to conceptualize, understand and investigate the interplay of personality and social relationships. This allows researcher to address a specific research question from a comprehensive perspective. It might also help to compare and evaluate existing theories and might serve as guideline for developing new theories.

In the following sections the basic PERSOC principles are outlined. Afterwards, we exemplarily show how the outlined principles can fruitfully be applied. We then describe the practical and theoretical implications of our framework, particularly how PERSOC can foster the integration of different research traditions, the detection of underestablished research domains, the clarification of mediating processes, and the definition of personality and social relationships. Finally, we outline some methodological recommendations that might help to improve the analytic quality of research on personality and social relationships.

\section{PERSOC PRINCIPLES}

We state four broad PERSOC principles as useful guidelines for characterizing the interplay of personality and social relationships (Table 1). In a nutshell, these basic principles include (i) the assumption of interdependent individual and relationship-related dispositions on an internal trait level (Disposition principle), (ii) the development and mutual influence of these dispositions over the course of time via mediating social interaction units on a state level (Interaction principle), (iii) the bidirectional and componential nature of social behaviours and interpersonal perceptions that make up social interaction units (Behaviour and Perception principle) and (iv) three classes of processes (dispositional expression processes, social interaction processes and dispositional development processes) that take place on the individual and dyadic levels and are restricted by the 'invisibility' of dispositions and perceptional components as well as the 'blindness' of dispositions and behavioural components (Processes principle).

We will now describe each of these four general 'rules of the game' in detail. To illustrate these complex dynamics, let us consider as an example the emerging friendship of Petra and Sonja, two students around 20 years old. They first met 4 months ago in the cafeteria of an art museum. Since then, they started going out together, talking about their everyday lives while sitting in a café, or watching videos at Petra's or Sonja's places. For the sake of simplicity, we will repeatedly refer to this example. All of our explanations, however, also hold for other relationships such as between Anton and Ben who are work-group members, Eva and Thomas who are dating each other, schoolboy Benjamin and his teacher Mrs Robinson, Katrin and her mother Elisabeth, patient Mary and her therapist Franz, the married couple Anita and Peter, as 
Table 1. Overview of PERSOC principles

\begin{tabular}{|c|c|c|}
\hline Principle & Description & Key aspects \\
\hline $\begin{array}{l}\text { Principle 1: disposition } \\
\text { principle }\end{array}$ & $\begin{array}{l}\text { Interdependent individual and relationship dispositions } \\
\text { are the building blocks of the personality-social } \\
\text { relationships interplay on an internal trait level }\end{array}$ & $\begin{array}{l}\text { Individual and relationship dispositions } \\
\text { Internal storage } \\
\text { Interdependence } \\
\text { Trait level }\end{array}$ \\
\hline $\begin{array}{l}\text { Principle } 2 \text { : interaction } \\
\text { principle }\end{array}$ & $\begin{array}{l}\text { Self- and relationship dispositions influence each other } \\
\text { and develop over the course of time via mediating social } \\
\text { interaction units on a state level }\end{array}$ & $\begin{array}{l}\text { Development (stability and change) } \\
\text { Mutual influence over time } \\
\text { Social interactions as mediators } \\
\text { State levell }\end{array}$ \\
\hline $\begin{array}{l}\text { Principle 3: behaviour and } \\
\text { Perception principle }\end{array}$ & $\begin{array}{l}\text { Actual social interactions are made up by social } \\
\text { behaviours and interpersonal perceptions, which are } \\
\text { each bidirectional and componential in nature }\end{array}$ & $\begin{array}{l}\text { Actual social behaviours and perceptions } \\
\text { Bidirectionality } \\
\text { Componentsl }\end{array}$ \\
\hline $\begin{array}{l}\text { Principle 4: processes } \\
\text { principle }\end{array}$ & $\begin{array}{l}\text { Processes that characterize the interplay of personality } \\
\text { and social relationships refer to the expression of } \\
\text { dispositions, social interaction processes and the } \\
\text { development of dispositions, take place on an individual } \\
\text { and dyadic level, and are restricted by the invisibility of } \\
\text { dispositions and perceptional components and the } \\
\text { blindness of dispositions and behavioural components }\end{array}$ & $\begin{array}{l}\text { Three classes of processes: dispositional } \\
\text { expression, social interaction and dispositional } \\
\text { development } \\
\text { Individual and dyadic level } \\
\text { Perceptional and dispositional invisibility } \\
\text { Behavioural and dispositional blindness }\end{array}$ \\
\hline
\end{tabular}

well as for the waiter Tom and each of his guests. ${ }^{1}$ Moreover, the following considerations can also be applied to larger groups of people such as sports teams, school classes or families, as they consist of multiple dyads.

\section{Principle 1: dispositions}

Disposition principle: On an internal trait level, interdependent individual and relationship dispositions (RD) are the building blocks of the personality-social relationships interplay.

According to our first principle, dispositions refer to an individual's own person (individual dispositions, ID) or to specific social partners of an individual (RD). These dispositions are thought to be internally located (i.e. they are not directly observable, but embedded in the individual's cognitive-affective-biological system) and at least relatively stable over time (trait level). Individual and RD are interdependent in the sense that they are logically intertwined and influence each other within the individual's internal system.

On an internal trait level, personality can be identified as the structure of ID. As typically conceptualized, ID can be defined as interindividually different and relatively stable internal characteristics of individuals (Funder, 1991; John, Naumann, \& Soto, 2008; McAdams \& Pals, 2006). These characteristics pertain to explicit or implicit mental

\footnotetext{
${ }^{1}$ Social relationships are usually defined as reoccurring and dynamically developing interactions between two people that cover a certain time span and include some kind of mental representation of the other person (e.g. Asendorpf \& Banse, 2000; Baumeister \& Leary, 1995; Hinde, 1979; Kelley et al., 1983). This definition excludes zero acquaintances. However, as each relationship starts with two people being unacquainted, this form of social relation needs to be considered to understand the development of social relationships. This is even more true because zero-acquaintance judgments may have meaningful consequences for future social outcomes and the development of social relationships (Back, Schmukle, \& Egloff, 2008, 2010a). To understand the relationship between Petra and Sonja, for instance, and particularly for how they became friends, it seems advisable to analyse what kind of people they were and what happened when they first met. Thus, PERSOC explicitly includes zero-acquaintance interactions.
}

representations of the self (e.g. self-esteem and self-concept of conscientiousness) and other objects (e.g. evaluations such as attitudes, interests and preferences), as well as to abilityrelated (e.g. intelligence), temperamental, motivational, physical and other more basic biological characteristics (e.g. hormone levels). They reach from very basic and extremely stable traits such as intelligence to more malleable surface traits (Asendorpf \& van Aken, 2003) such as selfesteem or leisure preferences. Each social partner of a relationship brings with her/him a specific pattern of ID. For example, Petra is more energetic and outgoing than most students and thinks of herself as a competent person. Sonja is rather anxious and shy and considers herself to be an artist. Sonja and Petra might share their interest for intellectual experiences and they might differ with respect to other preferences such as partying.

In a similar vein, social relationships are also present on an internal trait level as RD. In analogy to ID, RD can be defined as interindividually different and relatively stable internal characteristics of individuals directly related to specific others. Thus, in contrast to ID, RD characterize an individual in relation to a specific other individual. These characteristics encompass explicit or implicit mental representations of a specific relationship, including enduring feelings (e.g. love, relationship satisfaction, trust and intimacy), cognitions (e.g. perceived reciprocity, perceived personality traits, labelling someone as a friend and episodic memories) and relationship categorizations (e.g. Fiske, 1992; Neyer et al., in press). ${ }^{2}$ As most of these RD are more strongly influenced by two persons instead of only one

${ }^{2}$ For the sake of simplicity, we do not explicitly include variables such as objective indicators of relationship structure (e.g. contact frequency, relationship duration; Berscheid, Snyder, \& Omoto, 2004) or relationship status (e.g. married; Uller, 2003) in our model. Of course, however, the present model can be fruitfully used to understand why and how these dyadic outcome variables are influenced by social interactions via individual and relationship dispositions and vice versa. Other dyadic indicators like attitude similarity (Byrne, 1961) or biological indicators of relatedness (e.g. akin; Neyer \& Lang, 2003) are included in our model as relations between individual dispositions of two persons. 
person, they are usually not as stable as ID (Robins, Caspi, \& Moffitt, 2002). Some of them might be considered as almost trait-like 'social bonds' (Brown \& Brown, 2006). For example, in the course of the next few years, Petra may share a number of highly emotional experiences with Sonja, and may thus develop a stable sense of deep belongingness towards her. Other RD are more state-like, but still somewhat enduring perceptions of other people. For example, Petra tends to regard Sonja as a weak and vulnerable person in many (but not all) situations. Each individual has multiple more or less hierarchically organized and more or less stable $\mathrm{RD}$ for each social partner.

A special form of RD are reputations. Reputations can be defined as the way people are generally represented by others. From the perspective of our model, reputations of an individual refer to $\mathrm{RD}$ that are related to this person and shared by many social partners. They contain relevant information with respect to what we are like (Hofstee, 1994; Kolar, Funder, \& Colvin, 1996; Vazire, 2010; Vazire \& Mehl, 2008). In a certain way, reputations can also be seen as virtual external ID as they describe an individual but only exist as the sum of multiple RD stored in others' minds. ${ }^{3}$

In sum, we assume that the two forms of cognitiveaffective-biological representations - individual and RD comprise the internal storage of our personalities and our interpersonal relationships. According to PERSOC, individual and RD are interdependent. This line of reasoning is supported by cross-sectional research on the interplay of individual and RD: Self-report measures of personality are often substantially correlated with measures of stable relationship indicators. For example, this has been shown for extraversion and closeness of relationships (Neyer \& Asendorpf, 2001), optimism and perceptions of persons from the social network as highly supportive (Srivastava, McGonigal, Richards, Butler, \& Gross, 2006; Vollmann, Antoniw, Hartung, \& Renner, 2011), narcissism and decreased commitment to one's partner (Campbell \& Foster, 2002), and emotional stability and emotional closeness (Neyer \& Asendorpf, 2001) as well as relationship satisfaction (Karney \& Bradbury, 1997).

There are two reasons for this interdependency. The first reason is that they are conceptually related and partially resort to the same representations. Mental representations of the self, other objects and specific relationships are intertwined in networks of cognitive-affective associative and propositional representations (Smith \& DeCoster, 2000; Strack \& Deutsch, 2004). If, for example, Sonja is rather unsatisfied with herself per definition, it should be harder for her to believe in Petra as a valuable enrichment of her life. Moreover, temperamental and motivational dispositions that are thought to influence the general orientation of individuals should automatically also affect relationship-related dispositions. Petra's general approach tendencies, for instance, can be assumed to imply a motivational tendency to get to know Sonja.

${ }^{3}$ For both individual and relationship dispositions a hierarchical structure from more general dispositions (e.g. Big Five, love) to more specific and contextualized dispositions (e.g. coping styles, satisfaction with division of labour) can be assumed.
The second reason is that RD that are very important or that are similar with regard to many social partners can become ID. For example, RD regarding important social relationships are integrated into one's personal narratives (McAdams, 2008). Moreover, RD that a person has towards many social partners (e.g. trust towards many specific other persons) can influence one's generalized other (Bronfenbrenner, Harding, \& Gallwey, 1958) concept (e.g. others are trustworthy), which then would be an ID. This process can be seen as one internal mechanism behind the development of attachment styles (Shaver \& Mikulincer, 2006) or selfesteem (Back, Krause et al., 2009; Denissen, Penke, Schmitt, \& van Aken, 2008; Leary \& Baumeister, 2000). Enduring positive views towards others feed into positive self-views (see below: dispositional development processes).

\section{Principle 2: interactions}

Interaction principle: On a state level, self- and RD develop and influence each other over the course of time via mediating social interaction units.

The interplay of personality and social relationships cannot be fully understood without a developmental perspective. In line with longitudinal research and developmental theories of personality (Neyer \& Asendorpf, 2001; Neyer \& Lehnart, 2007) and social relationships (Berscheid \& Regan, 2005; Levinger, 1994), we assume that individual and RD are not totally stable, but develop over the course of time (Roberts \& DelVecchio, 2000). Not only may Sonja's and Petra's RD develop towards being mutually more trustful and towards more differentiated personality impressions, but their ID may develop as well. For example, Sonja may undergo a normative change towards less neuroticism and shyness (Roberts, Walton, \& Viechtbauer, 2006) and Petra may develop new music preferences.

Moreover, it is assumed that individual and RD influence each other over the course of time. Longitudinal research on the transactional development of personality and social relationships indeed has shown that (i) personality traits influence the development of RD such as popularity (Back, Schmukle, \& Egloff, 2010b), peer support (Asendorpf \& Wilpers, 1998), friendship (Selfhout et al., 2010) and romantic relationship satisfaction (Karney \& Bradbury, 1997) and (ii) social relations influence personality development (e.g. Branje, van Lieshout, \& van Aken, 2004; Lehnart, Neyer, \& Eccles, 2010; Neyer \& Lehnart, 2007; Roberts \& Bogg, 2004; Roberts \& Chapman, 2000; Scollon \& Diener, 2006; van Aken, Dennisen, Branje, Dubas, \& Goossens, 2006). Petra's extraversion as well as Petra's and Sonja's common interest in modern art may foster the developing intimacy between the women, although Sonja's higher shyness level makes her somewhat more cautious. In the long run, Sonja's developing trust in Petra might make Sonja more trusting and less shy in general.

We propose that social interaction units mediate (i) how individual and RD are generated, developed and maintained and (ii) how ID influence RD and vice versa. Although there is some degree of stability and change in individual and RD that is inherent to these constructs (Fraley \& Roberts, 2005), 
the development and mutual influence of these dispositions cannot be understood without the mediating processes. For instance, Petra and Sonja develop friendship and trust towards each other and influence each others' personalities by engaging in multiple and diverse social interactions with each other.

Social interaction units are actual social interactions between people with a circumscribable setting, onset and ending in which two or more people are at the very least aware of one another. Typical examples of social interaction units are activities such as direct or mediated (phone, e-mail) conversations, mutual planning, having a drink together, arguing, attending a meeting, sexual intercourse, watching a movie together, taking a walk together, having a sales talk, chatting, going clubbing, going on a date or explaining something. Sometimes social interaction units occur only sporadically (e.g. when Petra had to study for her BSc examination, she and Sonja met only twice a month) and sometimes a couple of social interaction units follow relatively immediately in a short period of time (e.g. when Petra finished her examinations, she and Sonja decided to go on a vacation together). Each social interaction unit is influenced by existing dispositions and feeds back into the development of these dispositions.

The central role of social interactions for the development of $\mathrm{RD}$ is in line with selective investment theory (Brown \& Brown, 2006), social endocrinology (Ellison \& Gray, 2009) and other theories of relationship development (Back, Schmukle, \& Egloff, 2010a; Gottman, 1994; Lang, Wagner, \& Neyer, 2009; Levinger, 1994). With regard to social bonds, Brown and Brown (2006), for instance, stated that 'bond consolidation may be enhanced...by shared (positive or negative) emotionally arousing experiences' ( $\mathrm{p}$. 7) and that 'following consolidation, the bond may be buffered further from decay or interference through rehearsal, generated internally or induced by interactions with the bond partner' (pp. 7-8).

The same logic applies to the formation and development of ID (cf. Swann \& Bosson, 2008; Zayas, Shoda, \& Ayduk, 2002). Sociometer theory, for example, posits that the development of a person's level of self-esteem is based on more or less positive social interactions, which indicate one's degree of social inclusion versus exclusion (Denissen et al., 2008; Leary \& Baumeister, 2000). Similarly, the fundamentals of attachment styles and close relationship formation have been traced back to early parent-child interactions (e.g. Simpson et al., 2007).

The influence of ID on RD should also be mediated by social interactions (Eaton \& Funder, 2003; Srivastava, Angelo, \& Vallereux, 2008). Petra's extraversion, for example, might have led to a cheerful first interaction, which in turn led Sonja to remember her as a person to have fun with. We want to emphasize that this process resembles the logic of the lens model (Brunswik, 1956): Characteristics that are not directly observable (ID) lead via observable cues (social interaction) to representations of these characteristics in another's mind (RD). In the same manner, the influence of RD on ID should function via social interactions. Sonja's developing trust towards Petra might lead her to be more

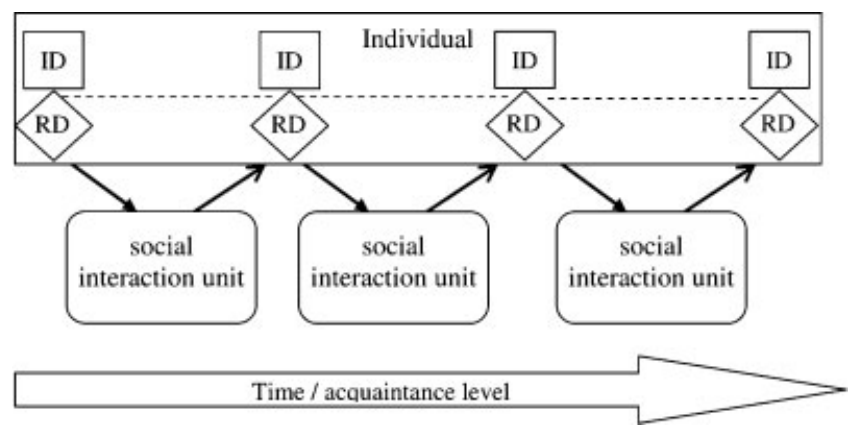

Figure 1. The meditational role of social interaction units. ID are depicted as squares, RD as diamonds, and social interaction units as horizontal radiused rectangles. Regular closed arrowheads refer to dispositional expression processes and open arrowheads refer to dispositional development processes.

open and self-disclosing than usual in her interactions with Petra, leading in turn to positive experiences, and ultimately to a more positive view of herself.

Besides developmental processes, dispositions are also important for understanding the ongoing course and continuity of social interaction units. Relatively stable ID of all social partners influence consecutive interactions in a similar manner (e.g. Knee, Lonsbary, Canevello, \& Patrick, 2005). Correspondingly, episodic memories as part of RD connect subsequent social interaction units because they result from prior social interactions and influence the initiation of new social interactions. Taken together, according to PERSOC, individual and RD develop and influence each other via social interaction units (see Figure 1).

\section{Principle 3: behaviours and perceptions}

Behaviour and perceptions principle: Actual social interactions consist of social behaviours and interpersonal perceptions that are bidirectional and componential in nature.

As PERSOC stresses, there are two groups of variables that constitute each social interaction: social behaviour and interpersonal perceptions. ${ }^{4}$ Social behaviour, including such diverse actions as smiling, helping, talking in a loud voice, listening carefully, ignoring, telling a joke or flirting, is difficult to define formally (Furr, 2009; Penke, 2009). Here

\footnotetext{
${ }^{4}$ In the absence of direct interactions, social interaction units may consist also of interpersonal perceptions alone. For example, this is the case when there is only one-sided awareness in a zero-acquaintance context (e.g. Petra recognizing Sonja sitting in the cafeteria). In such a case, one may speak of interpersonal perception units to distinguish them from social interaction units, which require social behaviour and perceptions and mutual awareness of both interaction partners. Such interpersonal perception units can nevertheless influence and be influenced by self- and relationship dispositions. They are often the starting point for subsequent social interaction units and developing relationships. As Petra notices that Sonja is reading a book by one of her (Petra's) favourite authors, she might decide that Sonja is an interesting person. This might lead Petra to approach Sonja and speak to her - the starting point of their first two-sided interaction unit. Moreover, relationship-related emotions and cognitions may be activated in between two-sided social interaction units. Such interpersonal perception units in the absence of the relationship partner may influence also the development of individual and relationship dispositions. Sonja may, for example, ruminate about her negative experiences with close relationships, undermining the development of trust towards Petra.
} 
we refer to social behaviour as including all actions within a social interaction unit that are produced by one interaction partner and that are potentially perceivable by another interaction partner. This definition refers to actual behaviours (Back \& Egloff, 2009; Baumeister et al., 2007) and encompasses, among others, nonverbal behaviours (e.g. Petra smiles at Sonja), paraverbal behaviours (e.g. Sonja has a tremulous voice), the verbal content of what people say (e.g. Petra praises Sonja's good taste) and observable physiological processes (e.g. Sonja blushes). Additionally, other social cues such as physical appearances (e.g. Sonja has a baby face) and behavioural residues (e.g. Petra's disorganized desktop) can function as behavioural equivalents - they stem from the organism of one interaction partner (but are not produced during the interaction unit) and are observable for the other. The production of all of these social behaviours and behavioural equivalents does not need to be intentional (Back, Schmukle, \& Egloff, 2009; Strack \& Deutsch, 2004) and the perception does not require consciousness (Evans, 2008; Smith \& DeCoster, 2000).

Interpersonal perceptions, broadly defined, include (i) inferences of another person's personality, cognitions, or emotional and motivational states (e.g. Petra perceives Sonja as distressed), (ii) a person's own feelings, cognitions and motivations towards other persons or interactions with other persons (e.g. Sonja likes Petra, Sonja perceives her interaction with Petra as tense), (iii) metaperceptions of other persons' perceptions (e.g. Sonja feels valued by Petra, Sonja thinks Petra thinks that she is too passive), as well as (iv) momentary self-perceptions related to the interaction (e.g. Petra feels happy, Sonja perceives herself as shy; e.g. Kenny, 1994). All of these interpersonal perceptions might include cognitive (e.g. Sonja thinks Petra is very unlike her), affective (e.g. Sonja is afraid that Petra is so dissimilar to her) and motivational (e.g. Sonja wants Petra to resemble herself) elements.

In accordance with Kenny (1994), PERSOC emphasizes the bidirectional nature of actual social behaviours and interpersonal perceptions. In real-life social interactions, people are not only actors who behave towards others, they are also partners with whom others interact. Petra is not only smiling at Sonja, she is also more or less smiled at by Sonja. Similarly, people are not only perceivers but at the same time targets being perceived by others. Sonja not only perceives Petra as intelligent, but Sonja is also perceived as more or less intelligent by Petra herself. Thus, social behaviours and interpersonal perceptions in social interactions are twosided.

Due to the bidirectional nature of social behaviour and interpersonal perceptions, interpersonal perceptions in social interactions not only refer to perceptions directed to others but also to metaperceptions and self-perceptions (see above). People are aware of the fact that others perceive them and that others have the potential to act towards them. As a consequence, they often engage in 'mind-reading' and develop metaperceptions about how others might perceive them, how others feel about them, and what others want from them (Back, Schmukle, \& Egloff, in press; Gleason, JensenCampbell, \& Ickes, 2009; Holmes, 2002; Kenny, 1994; Simpson, Orina, \& Ickes, 2003). For example, Sonja might be unsure about the impression that Petra has of her. She might worry about whether Petra likes her as much as she does. Petra, in turn, might realize that Sonja likes her, which makes her feel good. Moreover, interpersonal perceptions and behaviours in everyday situations are often closely related to self-perceptions. Within social interaction units, people have perceptions about how they are and what they think, feel and want. These self-perceptions influence the way they behave and perceive others and are affected by metaperceptions in a given situation. Sonja might, for example, hesitate to tell Petra about her inner feelings because she perceives herself to be immature and whiny, an impression she wants to avoid. However, she dares to describe her latest art project because she feels competent regarding this subject. Petra, in turn, might perceive herself to be an open person because she metaperceives that Sonja likes to talk with her about cultural and intellectual topics.

In line with the Social Relations Model (Back \& Kenny, 2010; Kenny, 1994; Malloy \& Kenny, 1986), we assume that behaviours and perceptions in social interactions are necessarily componential. Within real-life social interactions, each social behaviour towards another person (e.g. smiling) consists of three major components: a general tendency of the actor (actor effect), a general tendency towards the partner (partner effect), as well as of a specifically relational component that is independent of these two main effects (relationship effect). ${ }^{5}$ Petra's smiling at Sonja can be explained by her actor effect (she generally smiles a lot), Sonja's partner effect (people generally smile a lot at Sonja), or a specific relationship effect of Petra towards Sonja (she specifically smiles at her, more than she smiles at others and more than others smile at Sonja).

The same logic applies to interpersonal perceptions (e.g. liking and openness judgment). They always consist of a general tendency of the perceiver (perceiver effect), a general tendency towards the target (target effect), as well as a specifically relational perception that is independent of these two main effects (relationship effect). For example, consider Petra's perception of Sonja as a very open person. This perception might be due to Petra's high perceiver effect (perhaps she sees most people as very open), Sonja's high target effect (perhaps she is seen as very open by many others), or to an especially high relationship effect Petra has towards Sonja (perhaps Petra regards Sonja as very open, more than Petra regards others as open and more than others regard Sonja as open). A mixture of all three effects finally makes up Petra's perception of Sonja's openness. Sonja's liking of Petra can be decomposed in the same way. It is due to Sonja generally being a liker, Petra generally being popular and Sonja uniquely liking Petra. In an analogous way, any dyadic phenomenon can be decomposed into components (Back \& Kenny, 2010). ${ }^{6}$ See Table 1 for an

\footnotetext{
${ }^{5}$ This componential approach to social behaviours is in line with models that distinguish situation effects, person effects and situation-by-person interaction effects on social behaviour (Krueger, 2009; Snyder \& Ickes, 1985). It allows for the simultaneous estimation of all three kinds of effects within a social interaction context (Malloy \& Kenny, 1986).

${ }^{6}$ Behavioural equivalents that do not vary as a function of the interaction partner, such as certain aspects of physical appearance or behavioural residues, consist only of actor effects.
} 
Table 2. Examples of components of interpersonal perceptions and behaviours

\begin{tabular}{|c|c|c|c|}
\hline & \multicolumn{3}{|c|}{ Interpersonal perception } \\
\hline & $\begin{array}{l}\text { Perceiver effect (How does A } \\
\text { generally perceive others?) }\end{array}$ & $\begin{array}{l}\text { Target effect (How do others } \\
\text { generally perceive A?) }\end{array}$ & $\begin{array}{l}\text { Relationship effect (How does A } \\
\text { uniquely perceive } \mathrm{B} \text { ?) }\end{array}$ \\
\hline Personality judgment & Judgmental bias & Reputation & Unique impression \\
\hline Liking & Leniency & Popularity & Unique liking \\
\hline \multirow[t]{3}{*}{ Metaperception } & Chronic expectation & Judgmental reputation & Unique expectation \\
\hline & \multicolumn{3}{|c|}{ Social behaviour } \\
\hline & $\begin{array}{l}\text { Actor effect (How does A } \\
\text { generally behave towards others?) }\end{array}$ & $\begin{array}{l}\text { Partner effect (How do others } \\
\text { generally behave towards A?) }\end{array}$ & $\begin{array}{l}\text { Relationship effect (How does A } \\
\text { specifically behave towards B?) }\end{array}$ \\
\hline Observable choice behaviour & Choosiness & Interpersonal value & Unique preference \\
\hline Verbal content self-description & Self-presentation & Evoked self-presentation & Unique self-presentation \\
\hline Nonverbal behaviour & Nonverbal habit & Evoked nonverbal affordance & Unique nonverbal adaptation \\
\hline
\end{tabular}

overview of behavioural and perceptional components along with potential psychological labels of these components.

\section{Principle 4: processes}

Processes principle: Processes that characterize the interplay of personality and social relationships refer to the expression of dispositions, social interaction processes and the development of dispositions. They take place on individual and dyadic levels, and they are restricted by the invisibility of dispositions and perceptional components as well as the blindness of dispositions and behavioural components.

The processes principle is thought to disentangle the microprocesses underlying the development and dynamic interplay of personality and social relationships while accounting for the bidirectional and componential nature of social behaviours and interpersonal perceptions in social interaction units. PERSOC distinguishes three broad classes of processes: (i) dispositional expression processes (how personality and existing social RD influence behaviours and interpersonal perceptions within social interactions), (ii) social interaction processes (how the multitude of social behaviours and interpersonal perceptions of all social partners interact and form the natural flow of social interactions) and (iii) dispositional development processes (how the ongoing history of social interactions influences the development of individual personality as well as social relationship characteristics).

As described above, each social behaviour and interpersonal perception consists of two individual components (actor/partner effect and perceiver/target effect, respectively) and one dyadic component (relationship effect). Within the bounds of theoretical possibility, each individual component can influence and be influenced by other individual components and ID. Petra's tendency to smile at others may, for instance, influence how much others tend to like her. It may be influenced by her extraversion or her tendency to perceive others as friendly in social interactions. Relationship effects, by contrast, can only influence and be influenced by other dyadic components or emergent relations between individual aspects of the interaction partners. For instance, Sonja's unique tendency to selfdisclose towards Petra might lead to Petra's unique perception of Sonja as open-minded. It may be influenced by their similarity regarding interest in art. Thus, in each class of processes, individual and dyadic processes can be distinguished. Individual processes characterize aspects of individuals' dispositional expressions, social interactions and dispositional developments that generalize across social interaction partners. By contrast, dyadic processes characterize dispositional expressions, social interactions and dispositional developments that are unique for a specific dyadic constellation.

From a practical point of view, all kinds of behavioural and perceptional components and dispositions of all interaction partners can be related to each other, as long as they refer to the same level (individual vs. dyadic). However, we propose two main theoretical restrictions that are particularly noteworthy: the invisibility of dispositions and interpersonal perceptions and the blindness of dispositions and social behaviours.

Dispositions and perceptions are invisible because they are only internally represented. They must be expressed in terms of manifest behaviours in order to influence the interaction partner. For instance, interpersonal perceptions of interaction partners cannot directly influence each other as they are invisible mental states in different minds. Sonja being happy with their conversation cannot directly lead Petra to metaperceive this happiness and to think about meeting again next week. In order to influence an interpersonal perception of another person, an interpersonal perception needs to have behavioural consequences. Sonja, for example, would have to smile or to talk about meeting more often in order to influence Petra's metaperceptions. Dispositions do not directly cause perceptions of interaction partners either, but need to manifest themselves in observable behaviour or behavioural equivalents (physical appearances, behavioural residues). Petra's extraversion does not directly lead to Sonja thinking that Petra is funny. It is Petra's expressive and funny behaviour that mediates this effect.

Dispositions and behaviours are blind because they themselves cannot perceive behaviours of interaction 
partners, and thus, can only be influenced by them via interpersonal perceptions. Behaviours of interaction partners usually do not directly influence each other, as the behavioural cues are 'mindless' and, in this sense, 'blind' actions. A behaviour of one person has to be perceived (on a conscious or automatic level) by another person to influence his/her behaviour. For example, Sonja has to see Petra's antics or to hear her joke to start laughing. Dispositions are not directly influenced by behaviours of interaction partners either. Rather, social behaviours have to be observed to have an effect on dispositions. Sonja has to perceive Petra's positive social feedback to become more self-assured or to become more satisfied with their relationship. In our view, the invisibility and blindness rules are particularly helpful for specifying the ongoing course of processes that make up the dynamic interplay of personality and social relationships.

\section{PERSOC PROCESSES IN ACTION: EXPLAINING THE INTERPLAY OF PERSONALITY AND SOCIAL RELATIONSHIPS}

Now that we have described the 'rules of the game' - the variables and processes that are involved - we will take a closer look at different 'playing fields' to show how these principles can help in developing an understanding of the interplay of personality and social relationships. We will first use the emerging friendship of Sonja and Petra as an example to describe the different kinds of individual and dyadic processes within each class of processes (dispositional expression, social interaction and dispositional development). Afterwards, we will use teacher-student relationships and narcissists' social relationships as examples to show how these processes can be fruitfully applied. Finally, we will outline some other exemplary applications.

Figure 2 depicts some possible individual and dyadic dispositional-expression, social interaction and dispositional-development processes using one of Petra and Sonja's social interaction units and some of their self- and RD as examples. Sonja (a rather shy person who is interested in art) and Petra (who is extraverted and open and who has a reputation as a party queen) are now somewhat acquainted. Sonja has begun to develop trust in Petra and Petra starts to think of Sonja as her friend. They meet in a café and Sonja spontaneously starts to talk about her latest art project.

\section{Dispositional expression processes}

A selection of dispositional expression processes is shown on the left side of Figure 2. ID influence the way people generally behave towards others. These kinds of processes account for the predictive validity of personality for actual social outcomes aggregated across situations and interaction partners, respectively (e.g. Back, Schmukle, \& Egloff, 2009). Sonja, for example, as a rather shy person, may generally tend not to talk about private issues, and the extraverted Petra may generally tend to smile a lot. ID also shape general interpersonal perceptions and expectations (e.g. Back, Schmukle, \& Egloff, in press; Christensen \& Kashy, 1998; Holmes, 2002; Rusting, 1998). Petra's extraversion,

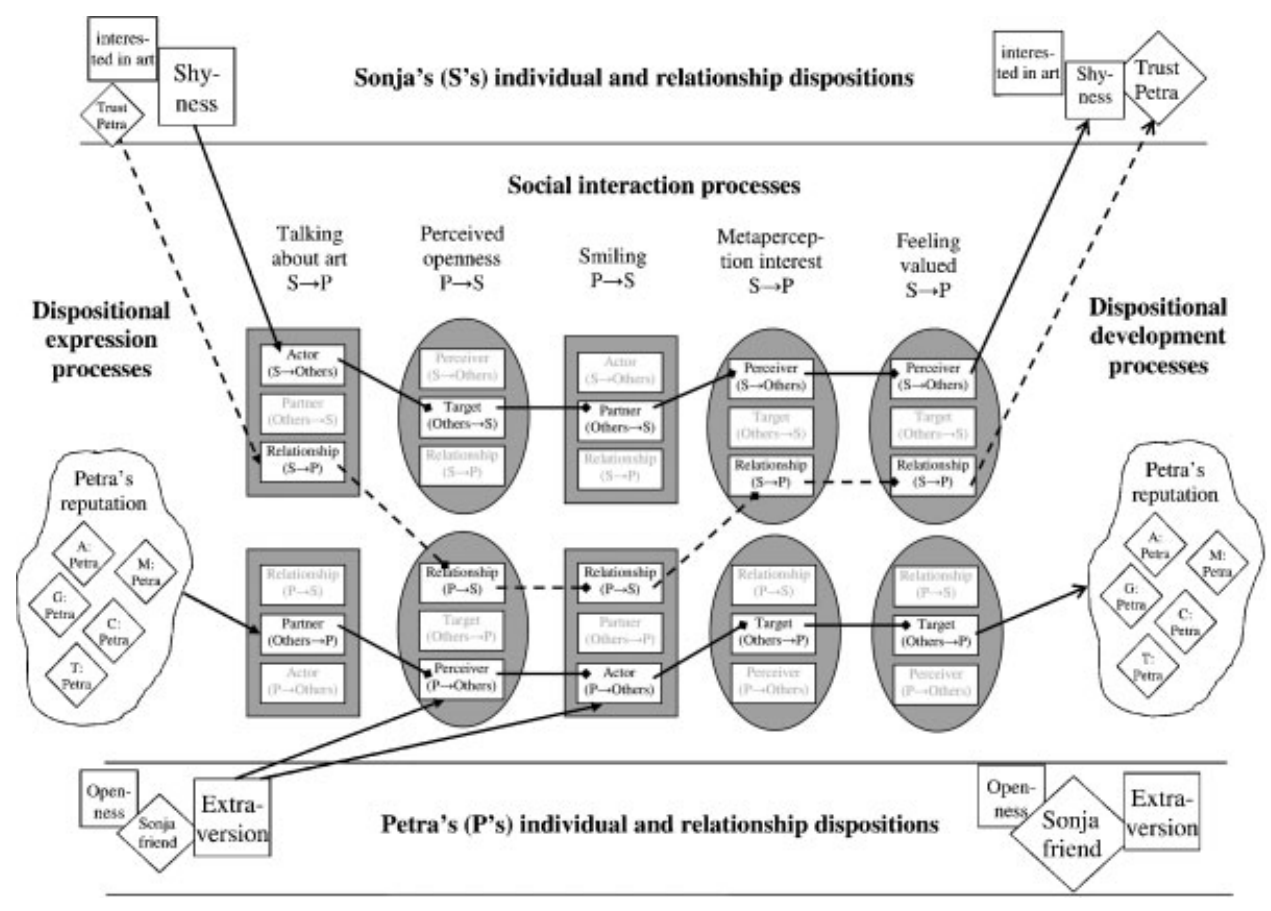

Figure 2. The interplay of dispositions, social behaviour and interpersonal perceptions in social interaction units. ID are depicted as squares and RD as diamonds, social interaction units as horizontal radiused rectangles, behaviours as vertical rectangles and interpersonal perceptions as vertical ovals. Regular closed arrowheads refer to dispositional expression processes, diamond-form arrowheads refer to social interaction processes and open arrowheads refer to dispositional development processes. Arrows with a solid line refer to individual processes whereas arrows with a dashed line refer to dyadic processes. S stands for Sonja, P for Petra, and other letters for other persons. For details, see text. 
for example, may explain why she tends to see others as open. RD that are shared by many social partners of an individual (reputations) influence the way others generally perceive and behave towards that individual in social interactions (e.g. Kniffin \& Wilson, 2004). Petra's reputation as a party queen may for instance prevent others from talking with her about topics like art.

$\mathrm{RD}$ that have developed in the course of prior interactions can lead directly to unique perceptions and behaviours in social interactions (e.g. Baldwin, 1992; Knee, 1998). Sonja, for example, has developed some trust in Petra and therefore dares to confide in Petra about her art project, although she usually does not. An interesting question is how these unique behaviours and perceptions come about. According to PERSOC, unique perceptions within a social interaction unit can originate also in the absence or in addition to existing unique relationship representations. We assume that depending on the perceiver's ID (e.g. Petra's openness), the social behaviour of another person (e.g. Sonja talking about unconventional topics) is specifically processed leading to a unique (idiosyncratic) impression (e.g. unique interest of Petra in Sonja; Back, Schmukle, \& Egloff, in press; Baumert \& Schmitt, 2009; Rusting, 1998). ${ }^{7}$ Appendix A gives an overview of possible effects of dispositions on social interaction components, procedural explanations and some exemplary applications.

Two recent studies underline the importance of different kinds of dispositional expression processes. Cuperman and Ickes (2009) examined the effect of personality on dyad members' behaviour and perceptions in initial, unstructured interactions. Personality predicted behaviour and perceptions in the form of actor effects (e.g. agreeable participants smiled more and perceived more rapport with the interaction partner), partner effects (e.g. agreeable participants were more nodded at and interaction partners enjoyed the interaction more) as well as actor-partner interactions (e.g. high disagreeableness of both partners led to uniquely low self-disclosure and low willingness to interact more with the partner in the future). Back et al. (in press) examined the influence of personality on real-life attraction at zero acquaintance. One cohort of psychology freshmen was investigated upon encountering one another for the first time. Personality traits, attraction ratings, and metaperceptions were assessed using a large round-robin design. Results showed that personality differentially predicted who was a liker and who expected to be liked (perceiver effects), who was popular and who was seen as a liker (target effects), as well as who liked whom and who expected to be liked by whom (relationship effects). Moreover, the influence of personality on attraction was mediated by observable physical, nonverbal and audible cues (for target effects) and by personality-cue interactions (for relationship effects).

\footnotetext{
${ }^{7}$ Structurally similar processes are hypothesized by social-cognitive models of personality, which explain the effect of person-situation interactions on behaviour via the personality-dependent processing of situational information (Caprara, Steca, Cervone, \& Artistico, 2003; Cervone \& Shoda, 1999; Mischel, 1973; Mischel \& Shoda, 1995; Rusting, 1998).
}

\section{Social interaction processes}

Social interaction processes including diverse behaviours and perceptions have been investigated in a wide range of research fields such as communication research (Hall, Coats, \& LeBeau, 2005), research on nonverbal behaviour and deception (DePaulo et al., 2003), parent-child relationships (Branje et al., 2005; Fraley \& Shaver, 1998) and romantic relationships (Gottman, 1994; Grammer, Kruck, \& Magnusson, 1998). The links between different individual and relational perceptional and behavioural social relations components have, however, seldom been investigated (with an exception being social relations research on the accuracy of personality judgments; e.g. Kenny et al., 2007). Kenny (1994, pp. 217-225) describes possible effects of behavioural components on perceptional components and vice versa. The social interaction processes outlined here built on these considerations.

Figure 2 shows some typical social interaction processes. The individual effects (actor and partner effects) timelines represent the typical course of this kind of interaction for person S (Sonja, see upper sequence of arrows) and person $\mathrm{P}$ (Petra, see lower sequence of arrows), respectively. These timelines encompass a number of different individual processes including (i) perceiver-perceiver processes (e.g. Sonja's general metaperception of others not being interested in her leads her to feel devalued), (ii) target-target processes (e.g. perceiving Petra as being interested may lead others to generally perceive her as valuing), (iii) actor-target processes (e.g. as Petra generally smiles a lot, others feel liked by her), (iv) partner-perceiver processes (e.g. because others seldom smile at Sonja, she has the feeling that she is disliked), (v) perceiver-actor processes (e.g. Petra's tendency to perceive many others as open-minded amplifies her general smiling behaviour) and (vi) target-partner processes (e.g. as others tend not to perceive Sonja as open-minded, they only seldom smile at her). ${ }^{8}$

The dyadic effects (relationship effects) timeline, by contrast, represents the interactional course that is unique to the specific relationship between two persons (Sonja and Petra, see middle sequence of arrows). Once there are unique relational perceptions, a variety of dyadic processes can be activated. Two perceptional relationship effects might influence each other within one individual. Sonja, for example, uniquely perceives Petra's interest in her art project, which makes her feel uniquely valued by Petra (more than she usually feels valued and more than others usually feel valued by Petra). Moreover, behaving in a unique way makes the other person uniquely perceive herself. As Sonja talks about her art project specifically with Petra (with whom others generally do not talk about art), Petra uniquely perceives Sonja as open-minded. Additionally, unique

${ }^{8}$ Please note that we do not refer to actor-partner or partner-actor associations as processes because of behavioural blindness, and we do not refer to perceiver-target, target-perceiver, perceiver-partner or target-actor associations as processes because of perceptional invisibility. Technically, one can of course additionally analyse these associations, and they often refer to interesting and important phenomena. However, we would not interpret these associations as direct causal links (processes) because they require additional mediational explanations (see Appendix B). 
interpersonal perceptions lead to unique actions by an individual. Petra's unique perception of Sonja as openminded makes her smile more at Sonja than she usually does with others (and more than Sonja usually receives). ${ }^{9}$

Together the individual and dyadic timelines make up the actual observable social interaction between two individuals. Appendix B gives an overview of computable associations between social interaction components, procedural explanations and some exemplary applications.

\section{Dispositional development processes}

As we have emphasized before, individual and RD are subject to change and they influence each other. According to PERSOC, multiple subsequent social interaction units are the driving forces behind these longitudinal developments. On an individual level, generally perceiving others in a certain way (especially metaperceiving their perceptions of oneself) in social interactions (perceiver effect) influences ID (e.g. Back, Krause, et al., 2009; Denissen et al., 2008; Penke, Todd, Lenton, \& Fasolo, 2007). For example, Sonja, who seldom feels valued by others, may develop higher scores on shyness. Additionally, generally being perceived by others in a certain way (target effect) in social interactions influences one's reputations (RD that are shared by many of the social partners of an individual). If others begin to feel valued by Petra often, this might gradually change her reputation from a superficial party queen to a more sensitive person. On a dyadic level, uniquely perceiving another person in a social interaction can influence one's RD regarding this person. Sonja, for instance, uniquely perceives Petra's valuation of herself, which strengthens her trust in Petra. Because of the interdependence of individual and RD, such changes in RD may gradually also change ID, for instance, Sonja's shyness (see above). Appendix $\mathrm{C}$ gives an overview of possible effects of social interaction components on dispositional development, procedural explanations and some exemplary applications.

Taken together, individual and dyadic processes of dispositional expression, social interaction and dispositional development build the theoretical toolbox for explaining all kinds of dynamics of the personality-social relationship interplay. Accounting for this complex nature of the personality-social relationship interplay and the diversity of the dynamic social interaction processes involved has important consequences for how we conceptualize, understand, and investigate personality and social relationships.

\footnotetext{
${ }^{9}$ As for the individual-social interaction processes, there are other possible relational associations that do not represent direct processes, but rather represent indirect associations that are due to additional relational mediators. For instance, unique relational perceptions do not directly influence unique perceptions or actions of the interaction partner (perceptional invisibility) and unique behaviours do not directly cause unique behaviours of the interaction partner (behavioural blindness; see Appendix B).
}

Applied research example 1: using PERSOC to explain the effects of students' characteristics and teachers' stereotypes on students' academic achievements

One obstacle to a correct and fair assessment in the classroom consists of stereotypes regarding the relation between students' observable characteristics and their cognitive abilities: often, students' characteristics that are unrelated to cognitive abilities (e.g. social anxiety and gender) are nevertheless used by teachers to infer the students' abilities. Let us consider socially anxious students as a potential example. Although socially anxious students initially have the same actual cognitive abilities, low teacher preferences might lead to less academic achievement and lower grades as compared to self-assured and verbally expressive individuals (cf. Arbeau, Coplan, Weeks, 2010; Chen, Wang, \& Wang, 2009; Rubin \& Asendorpf, 1993). In line with the developmental social interaction approach of PERSOC, this might be explained via teachers' stereotypic (and invalid) perceptions of socially anxious students and subsequent reoccurring teacher-student interactions, which, in the long run, produce the lower academic achievements of the socially anxious.

Using PERSOC, this self-fulfilling prophecy explanation of academic underachievement (cf. Jussim \& Harber, 2005; Rosenthal \& Jacobson, 1992; Snyder \& Swann, 1978) can be analysed in a differentiated way. Figure 3 shows the involved dispositional expression, social interaction and dispositional development processes using one of multiple subsequent teacher-student interactions as an example. These processes can be analysed from the perspective of the student being misjudged by teachers (target self-fulfilling prophecy processes; see Figure 3, upper sequence of arrows A1A9), the teacher misjudging students (perceiver selffulfilling prophecy processes; see Figure 3, lower sequence of arrows B1-B6), or the relationship of a specific teacher uniquely misjudging a certain student (dyadic self-fulfilling prophecy processes; see Figure 3, middle sequence of arrows C1-C6).

Target self-fulfilling prophecy: A socially anxious student is less expressive and shows rather withdrawn behaviour in the classroom (A1). Due to a generally shared stereotype, this behaviour is perceived as a sign of academic incompetence by teachers (A2), leading them to give negative feedback and less intellectual stimulation to the student (A3). The negative feedback is metaperceived by the student (A4), which fosters his/her social anxiety level (A5) and leads to actually lower levels of performance (A6) and undermining the development of academic competence (A7). Moreover, the lower performances are perceived by teachers (A8), strengthening the student's reputation as incompetent (A9).

Perceiver self-fulfilling prophecy: A teacher with a negative view on students' abilities may generally tend to view students as incompetent (B1) and accordingly he/she generally gives a lot of negative feedback and little intellectual stimulation (B2). As a consequence, students of this teacher metaperceive this devaluation (B3) and indeed show lower performance (B4). This is perceived by the 


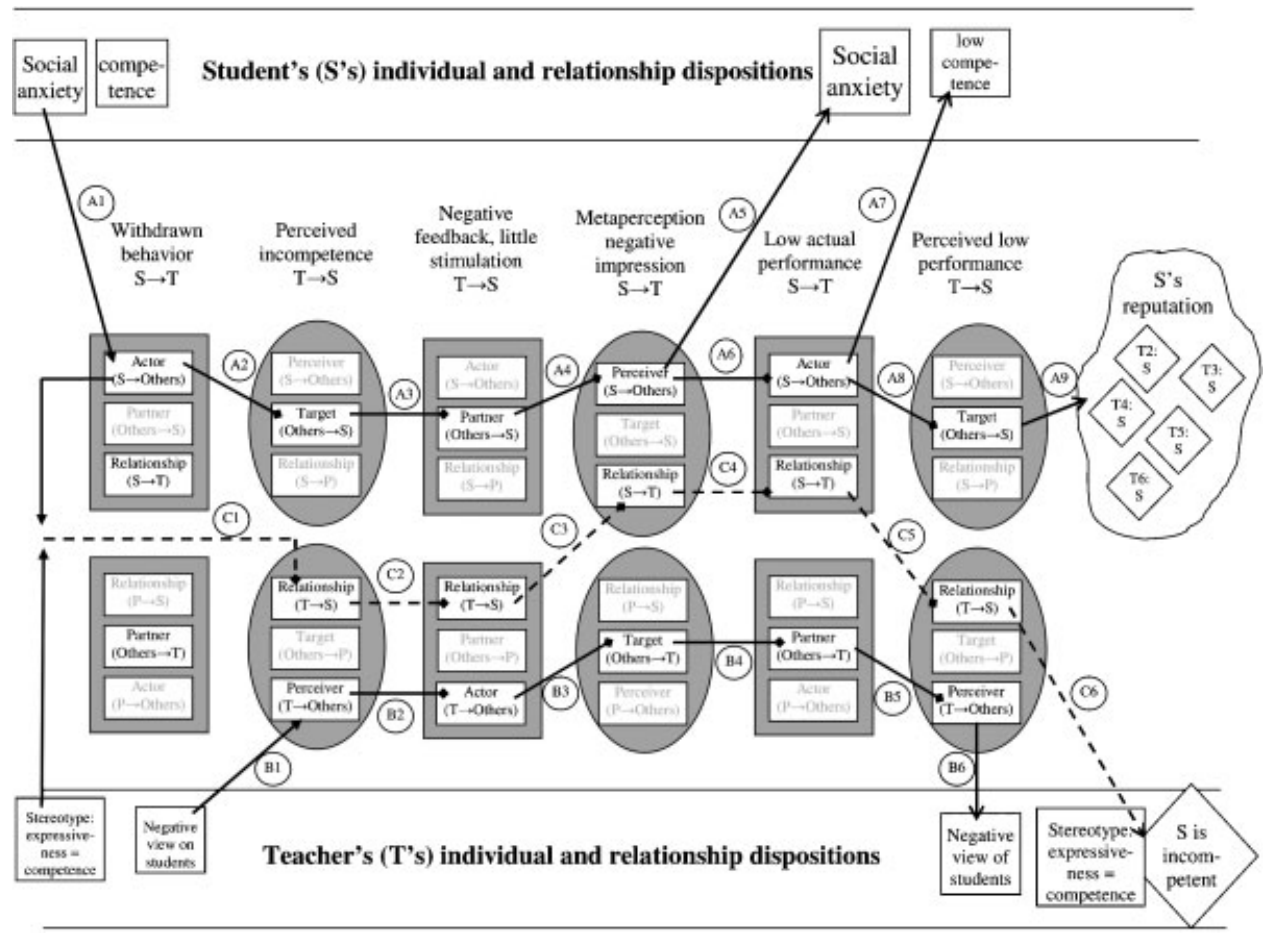

Figure 3. Using PERSOC to explain the development of academic underachievement of socially anxious students via teacher stereotypes and self-fulfilling prophecy processes in teacher-student interactions. ID are depicted as squares and RD as diamonds, social interaction units as horizontal radiused rectangles, behaviours as vertical rectangles and interpersonal perceptions as vertical ovals. Regular closed arrowheads refer to dispositional expression processes, diamondform arrowheads refer to social interaction processes and open arrowheads refer to dispositional development processes. Arrows with a solid line refer to individual processes, whereas arrows with a dashed line refer to dyadic processes. T1 stands for a specific teacher, $\mathrm{S}$ for students and T2-T6 for other teachers. There are three kinds of processes: target self-fulfilling prophecy processes (A1-A9), perceiver self-fulfilling prophecy processes (B1-B6) and dyadic selffulfilling prophecy processes (C1-C6). For details, see text.

teacher (B5), confirming his/her negative view on students' abilities (B6).

Dyadic self-fulfilling prophecy: Teachers differ with respect to how much they share the stereotype that expressiveness is a sign of competence or not. Thus, a teacher with a particularly strong stereotype may uniquely perceive a socially anxious student to be incompetent due to his/her uniquely strong interpretation of withdrawn behaviour as a sign of incompetence (C1). Based on this unique negative perception, the teacher gives more negative feedback and less intellectual stimulation to the student (C2), which leads the student to perceive the uniquely negative feedback (C3) and to show lower performance with this specific teacher $(\mathrm{C} 4)$. This unique low achievement is perceived by the teacher (C5), leading to the development of a negative RD towards the socially anxious student, which also strengthens the teacher's stereotypes (C6).

Consequences for research on academic underachievement: The outlined dynamics can also be used to explain the effects of stereotypes on achievement differences between boys and girls (e.g. Beilock, Gunderson, Ramirez, \& Levine, 2010; Brown \& Josephs, 1999; Nosek et al., 2009) or between students with higher versus lower socioeconomic status (Robbins, Lauver, Davis, Langley, \& Carlstrom, 2004). Academic underachievement due to invalid stereotypic teacher perceptions is certainly an important problem with wide ranging negative individual and collective consequences. Using the proposed framework, the dynamics underlying this phenomenon can be analysed in a finegrained way, including (i) the consideration of dispositions, behaviours and perceptions of all individuals involved, (ii) the dynamic developmental perspective with detailed analyses of the mediating social interaction processes and (iii) subaspects of the phenomenon that have seldom been analysed before (particularly perceiver and dyadic selffulfilling prophecy processes). Such analyses may additionally incorporate the influence of peer reactions in conjunction with the students' and teachers' personality characteristics and their social interactions (e.g. Mercer \& DeRosier, 2008). In sum, PERSOC analyses might lead to a more differentiated understanding of academic underachievement, its determinants and consequences, and ultimately to more effective interventions.

\section{Applied research example 2: using PERSOC to understand the social consequences and the development of narcissism}

Narcissism is associated with a number of interpersonal problems and paradoxes, particularly more unstable and conflictuous close relationships (e.g. Buss \& Shackelford, 1997; Campbell \& Foster, 2002). Current theoretical models 
explain these negative interpersonal consequences as a function of narcissists' connection with traits like impulsivity (Vazire \& Funder, 2006), or dynamic self-regulatory processes central to which is gaining and maintaining favourable self-views (Morf \& Rhodewalt, 2001). The exact micro-processes underlying the effects and development of narcissism, however, are not specified and await empirical investigation. Detailed PERSOC analyses can help to better understand four of the most relevant aspects of the narcissism-relationship interplay: (i) narcissists' reputations, (ii) narcissists' negative view of others, (iii) narcissists' unique relationships and (iv) the development and maintenance of narcissism.

Understanding narcissists' reputation: A curious course of impression formation: Whereas narcissists make a positive first impression (Back, Schmukle, \& Egloff, 2010b), they have a bad reputation in the long run (e.g. Anderson, Ames, \& Gosling, 2008; Paulhus, 1998). According to PERSOC, these contradictory effects of narcissism on the positivity of people's reputations are due to narcissists' typical interactive behaviours in observable social interaction units typical for zero or short-term acquaintance and long-term acquaintance, respectively. In a get-to-know conversation narcissists tend to generally show expressive behaviour (e.g. high actor effect for smiling), leading to generally favourable impressions by others (e.g. high target effects for perceived trustworthiness and liking). This can additionally be fostered by the social partners' positive reactions towards narcissists (e.g. high partner effect for laughing), which reinforces narcissists (e.g. high perceiver effect for feeling admired), leading to even more self-assured and entertaining behaviours (e.g. high actor effect for telling jokes), and so forth. Ultimately, these interactive dynamics should lead to a positive reputation in a short-term acquaintance context. By contrast, narcissists' typical behaviours are less adaptive in interaction units at long-term acquaintance. For example, in a problem solving discussion, narcissists' general tendency to be to be expressive and dominant, yet inattentive (e.g. low actor effect for listening carefully to what others say) might generally lead others to view them negatively (e.g. high target effect perceived egoism). As a consequence, others might tend to provide negative feedback to narcissists (e.g. high partner effect for criticism), which might then be perceived as a sign of others' negative intentions by narcissists (e.g. high perceiver effect for perceived intention to outplay oneself) leading to even more undesirable behaviours (e.g. high actor effect for aggressiveness). Over the course of many such interaction units narcissists' reputations will worsen.

Understanding narcissists' negative view of others: Similar fine-grained analyses might help to understand the negative view narcissists have of others (e.g. Foster, Shrira, \& Campbell, 2006; Morf \& Rhodewalt, 1993). In particular, disentangling the various specific interaction components can help to understand to what extent narcissists' negative view of others are a stable intrapersonal feature inherent to the trait of narcissism and/or a consequence of rejection by others (due to the suboptimal interactive dynamics outlined above).
Understanding narcissists' unique social choices: PERSOC analyses can also reveal the interactive dynamics underlying the narcissists' unique relational choices. Individuals who have very positive and highly valued qualities should for example have a special appeal for narcissists. On the one hand, narcissists might be uniquely attracted to such individuals because they have the potential to provide narcissists with popularity and importance (Campbell, 1999). On the other hand, such individuals might represent a unique threat for narcissists who might perceive them as rivals striving for glory and others' admiration. PERSOC analyses can reveal what kind of appearances and social behaviours of potential social partners are uniquely processed by narcissists, leading to multiple unique perceptions (e.g. high/low relationship effect liking) and unique actions (e.g. high/low relationship effect direct communication) as the mediating processes leading to unique social choices of narcissists.

Understanding the development of narcissism: Theories of narcissistic development have concentrated on the influence of parental devaluation, parental overvaluation or a combination of both (Otway \& Vignoles, 2006). Interestingly, a similar pattern of social reactions applies to peers of adult narcissists: admiration for superficial reasons at zero acquaintance as well as rejection and a lack of warmth and acceptance later on. Research on the conditions and processes that are responsible for the development and maintenance of narcissists' problematic self-concept would profit from detailed PERSOC analyses of (i) the social partners' interactive behaviours, (ii) the way these behaviours are perceived and incorporated into the narcissists' grandiose self-concept and (iii) the active role of narcissists in provoking these behaviours.

Theoretical implications: The outlined application of PERSOC to the field of narcissism describes a rich research program that can lead to new and important findings. It would be particularly helpful to understand by means of which exact social interaction dynamics narcissism influences social relationship qualities and vice versa. In doing so, a PERSOC approach to narcissism would allow to directly test competing theoretical accounts of narcissism by means of thorough process analysis (e.g. distinguish between automatic impulsive behaviours that disturb the course of social interactions versus selfpresentational behaviours and strategic devaluation of others in the service of positive self-views as mediators of the negative interpersonal consequences of narcissism). By providing detailed processual insights and a common glossary, PERSOC would also help to specify, broaden and integrate different theoretical accounts of the intra- and interpersonal dynamics of narcissism.

\section{Other applications}

The outlined principles and processes may inform many other basic or applied research domains. To give some examples, PERSOC may be helpful for understanding (i) the influence of romantic relationship partners' dispositions on relationship quality via ongoing social interactions 
(Gottman, Coan, Carrere, \& Swanson, 1998; Schöder- Abé and Schütz, 2011), (ii) the social interaction processes that foster the development and maintenance of social anxiety disorders (e.g. Schultz \& Heimberg, 2008), (iii) friendship development (Denissen et al., 2011), (iv) zero-acquaintance judgments (Back, Schmukle, \& Egloff, in press), (v) reciprocity (Back, Penke, Schmukle, Sachse, Borkenau, \& Asendorpf, 2011), meta-accuracy (Back, Penke, Schmukle, \& Asendorpf, 2010) and consequential outcomes (Asendorpf, Penke, \& Back, in press) of mate choices, (vi) social support exchange processes (Vollmann et al., 2011), the influence of dispositions and social interaction processes on (vii) family dynamics (Wrzus, Wagner, Baumert, Lang, \& Neyer, 2011), (viii) employee selection (Barrick, Shaffer, \& DeGrassi, 2009; Tay, Ang, \& Van Dyne, 2006), or (ix) group effectiveness (Berry and Stewart, 1997; Robert \& Cheung, 2010) or (x) for understanding the concrete social interaction processes that ultimately foster or dampen people's selfesteem over the course of time (cf. Back, Krause, et al., 2009; Denissen et al., 2008).

\section{IMPLICATIONS}

We hope that PERSOC will help to foster integrative research on personality and social relationships. In our view, the most valuable benefit of PERSOC is that it provides a common glossary for the study of personality and social relationships. It contains straightforward definitions, principles and potential processes that can be applied to a diverse range of research areas, including all kinds of personality traits and social relationships at all stages of acquaintanceship. Such a common language and toolbox allows researchers from different theoretical traditions and research fields to communicate economically and to compare their theoretical and empirical analyses. This has a number of practical and theoretical advantages.

First, it allows for learning from each other and communicating theoretical concepts and empirical approaches across research fields. Second, it urges researchers from different fields to be more precise in justifying their theories and research approaches because they are directly comparable to others. Third, it allows for comparing and integrating results from different research traditions, and thus, for identifying communalities and differences in the processes that characterize different relationships and levels of acquaintance.

Fourth, the collection of basic principles and possible processes allows for the screening of existing research fields and for detecting research questions that have not yet been investigated, as well as for the advancement of work in underestablished research domains. A strong focus of PERSOC is on understanding the mediating social interactional processes that explain effects of personality on social relationships (e.g. Why does agreeableness lead to higher relationship quality?), effects of social relationships on personality (e.g. Why do romantic relationships reduce neuroticism?) or effects between social interaction components (e.g. Why is liking not necessarily related to being liked?). Understanding these processes will help also in identifying specific conditions under which personality influences social relationships and vice versa (moderators). PERSOC is also particularly well-suited to advance our understanding of relationship transitions. The developmental perspective, the consistency of variables across kinds of relationships and levels of acquaintanceship, as well as the definition of microprocesses that change individual and RD and mediate their mutual influence facilitate fine-grained analyses of how people's relations with social partners develop into new forms of relationships (e.g. transitions from zero acquaintance to friendship or from romantic relationship to parenthood). It also allows for investigating in detail the developmental course of each type of social relationship.

Fifth, PERSOC can be seen as a metatheoretical framework that provides a basic conceptual structure for developing or evaluating domain-specific theories on the interplay of personality and social relationships with specific assumptions and predictions. The basic principles outlined in the present article apply to all kinds of research domains and questions. Theories of social relationships should consider (or could be completed to consider) individual and RD as well as their longitudinal interplay, the mediating role of actual social interaction units, the bidirectional and componential nature of social behaviour and interpersonal perceptions, and their sequential course within social interaction units.

Sixth, PERSOC has consequences for how to define personality and social relationships in general. The framework itself does not include personality or social relationships as a separate group of variables. Instead, PERSOC understands personality and social relationships as the result of several kinds of variables and their dynamic interactions. We refrained from equating personality with ID because personality can also be understood as part of an individual's actions and perceptions as well as an individual's reputation. From our perspective, personality is the sum of and the interplay between all dispositions, social behaviours and interpersonal perceptions that characterize an individual. This includes how people are biologically wired and how they represent themselves (ID), how people are represented by others (reputations), and are generally perceived by others in social interactions (target effects for interpersonal perception), how people generally perceive others in social interactions (perceiver effects for interpersonal perception), how people generally act (actor effects for social behaviour) and how others generally act towards them in social interactions (partner effect for social behaviour). We also did not equate social relationships with recurring social interactions because recurring interactions are represented also in individuals' dispositions. From this view, social relationships can be defined as the sum of and the interplay between all dispositions, social behaviours and interpersonal perceptions that specifically characterize at least two defined persons. This includes all kinds of individual dispositional interactions and RD as well as unique social behaviours and interpersonal perceptions. 


\section{PERSOC AND THE SITUATION}

PERSOC distinguishes three main sources of systematic variance in social behaviours and interpersonal perceptions within social interaction units: actor/perceiver, partner/target and relationship effects. This is in line with the social relations model (Back \& Kenny, 2010; Kenny, 1994). Moreover, the componential aspect of PERSOC is analogous to interactive models of behaviour determination that conceptualize behaviours as the result of the person, the situation and the interaction of both (Endler \& Hunt, 1966; Mischel \& Shoda, 1995). PERSOC uses the social interaction partner as the most prominent feature of social situations and analyses all kinds of behavioural and perceptional effects on the level of the actor/perceiver, the partner/target and their interaction, the relationship (cf. Malloy \& Kenny, 1986).

In the current version, PERSOC does not explicitly include situational context variables as predictors of social interactions. Characteristics of the situational context (i.e. systematic differences between situations other than differences due to the interaction partner; i.e. systematic differences between situations other than differences due to the interaction partner; e.g. time of day, location, presence of heat, noise, or food, scarce resources inducing competitiveness, cultural rules restricting social interactions) might, however, systematically influence perceptions and social behaviours within social interaction units. These differences might, moreover, interact with both characteristics of the actor (or perceiver) as well as characteristics of the partner (or target), in predicting social outcomes. Following the componential logic of PERSOC and adding the situational context as an additional source of systematic variance, social behaviours (or interpersonal perceptions) could be decomposed into the following seven sources of variance: actor, partner, context, actor $\times$ partner (relationship), actor $\times$ context, partner $\times$ context and actor $\times$ partner $\times$ context, leading to even more fine grained analyses of personality and social relationships.

\section{METHODOLOGICAL RECOMMENDATIONS}

On a methodological level, PERSOC can help in specifying adequate research designs and analyses, and thus, can help in improving the analytic quality of research on personality and social relationships. A detailed consideration of design, measurement and analyses is beyond the scope of the present paper. The implementation of many PERSOC analyses requires specific dyadic designs, statistical analyses that account for the dyadic nature of data and appropriate software solutions (see Back \& Kenny, 2010; Kenny, Kashy, \& Cook, 2006; http://davidakenny.net/srm/srmp.htm; http:// www.persoc.net; for overviews, further readings, and many helpful guidelines and tools).

Most importantly, adequate data should be gathered. The PERSOC framework stresses that it can be extremely fruitful to (i) assess individual and RD of all relationship partners, (ii) observe actual social interactions between relationship partners, (iii) assess actual social behaviours and inter- personal perceptions of all relationship partners within these interactions, (iv) assess social behaviours, interpersonal perceptions and relationship representations towards and from multiple partners and (v) assess all measures repeatedly (cf. Cooper \& Sheldon, 2002). In doing so, one should be careful to choose adequate measures. Self- and RD can be assessed by standard direct (e.g. questionnaires) or indirect (e.g. Implicit Association Tests) measures. Interpersonal perceptions should be measured as promptly as possible within the social interaction, and actual social behaviours should be measured by direct behavioural observation (Back \& Egloff, 2009).

\section{CONCLUSIONS}

The recent years have been accompanied by a number of interdisciplinary approaches to personality and social relationships (Baumeister, 1999; Cooper, 2002; Vohs \& Finkel, 2006; Wood et al., 2008) and a renewed interest in actual social phenomena (Baumeister et al., 2007; Cialdini, 2009; Furr, 2009). Important integrative models have been applied and further developed, particularly the lens model (Brunswik, 1956; Borkenau \& Liebler, 1992; Funder, 1999; Gosling, Ko, Mannarelli, \& Morris, 2002) and other behavioural process models (Donnellan et al., 2005; Simpson et al., 2007), the social relations model (Back \& Kenny, 2010; Kenny, 1994), and transactional models of personality and social relationship development (Swann \& Bosson, 2008; Roberts et al., 2005).

Here, we have presented PERSOC, a model that builds on these ideas and integrates them into a unified framework. It describes principles and processes by which dispositions, social behaviours and interpersonal perceptions characterize the interplay and development of personality and social relationships. PERSOC can be applied to all different kinds of social relationships (everyday, work, pedagogical/educational, clinical, friendship, family and romantic) at any stage of acquaintance (zero to long-term acquaintance). We hope that PERSOC will provide an avenue for analysing a wide variety of research topics and will be another step towards an integrative science of personality and social relationships.

\section{ACKNOWLEDGMENTS}

This research was supported by Grant BA 3731/1-1 and Grant BA 3731/2-1 (network 'Personality and Social Relationships', www.persoc.net) from the German Research Foundation (DFG) to Mitja Back. We thank Michael Dufner, Tanja Gerlach, Sarah Hirschmüller, Roos Huttemann, Albrecht Küfner, Katrin Rentzsch and Juliane Stopfer for fruitful discussions and helpful comments on an earlier draft of this manuscript.

\section{REFERENCES}

Altman, I., \& Taylor, D. A. (1973). Social penetration: The development of interpersonal relationships. New York: Holt, Rinehart, and Winston.

Anderson, C., Ames, D. R., \& Gosling, S. D. (2008). Punishing Hubris: The perils of overestimating one's status in a group. Personality and Social Psychology Bulletin, 34, 90-101. 
Arbeau, K. A., Coplan, R. J., \& Weeks, M. (2010). Shyness, teacherchild relationships, and socio-emotional adjustment in grade I. International Journal of Behavioral Development, 34, 259-269.

Asendorpf, J., \& Banse, R. (2000). Psychologie der Beziehung. Bern: Huber.

Asendorpf, J. B., Penke, L., \& Back, M. D. (in press) From dating to mating and relating: Predictors of initial and long-term outcomes of speed-dating in a community sample. European Journal of Personality.

Asendorpf, J. B., \& van Aken, M. A. G. (2003). Personalityrelationship transaction in adolescence: Core versus surface personality characteristics. Journal of Personality, 71, 629-666.

Asendorpf, J. B., \& Wilpers, S. (1998). Personality effects on social relationships. Journal of Personality and Social Psychologie, 74, 1531-1544.

Back, M. D., \& Egloff, B. (2009). Yes we can! A plea for direct behavioral observation in personality research. European Journal of Personality, 23, 403-405.

Back, M. D., \& Kenny, D. A. (2010). The Social Relations Model: How to understand dyadic processes. Social and Personality Psychology Compass 4, 855-870.

Back, M. D., Krause, S., Hirschmüller, S., Stopfer, J. M., Egloff, B., \& Schmukle, S. C. (2009). Unraveling the three faces of selfesteem: A new information-processing sociometer perspective. Journal of Research in Personality, 43, 933-937.

Back, M. D., Penke, L., Schmukle, S. C., Sachse, K., Borkenau, P., \& Asendorpf, J. B. (2011). Why mate choices are not as reciprocal as we assume: The role of personality, flirting, and physical attractiveness. European Journal of Personality.

Back, M. D., Penke, L., Schmukle, S. C., \& Asendorpf, J. B. (2010). Knowing your own mate value: Sex-specific personality effects on the accuracy of expected mate choices. Manuscript submitted for publication.

Back, M. D., Schmukle, S. C., \& Egloff, B. (2008). Becoming friends by chance. Psychological Science, 19, 439-440.

Back, M. D., Schmukle, S. C., \& Egloff, B. (2009). Predicting actual behavior from the explicit and implicit self-concept of personality. Journal of Personality and Social Psychology, 97, 533-548.

Back, M. D., Schmukle, S. C., \& Egloff, B. (2010a). From first sight to friendship: A longitudinal social relations analysis of stability and change in interpersonal attraction. Manuscript submitted for publication.

Back, M. D., Schmukle, S. C., \& Egloff, B. (2010b). Why are narcissists so charming at first sight? Decoding the narcissismpopularity link at zero acquaintance. Journal of Personality and Social Psychology, 98, 132-145.

Back, M. D., Schmukle, S. C., \& Egloff, B. (in press) A closer look at first sight: Social relations lens model analyses of personality and interpersonal attraction at zero acquaintance. European Journal of Personality.

Back, M. D., Stopfer, J. M., Vazire, S., Gaddis, S., Schmukle, S. C., Egloff, B., et al. (2010). Facebook profiles reflect actual personality, not self-idealization. Psychological Science, 21, 372-374.

Baldwin, M. W. (1992). Relational schemas and the processing of social information. Psychological Bulletin, 112, 461-484.

Barrick, M. R., Shaffer, J. A., \& DeGrassi, S. W. (2009). What you see may not be what you get: Relationships among selfpresentation tactics and ratings of interview and job performance. Journal of Applied Psychology, 94, 1394-1411.

Baumeister, R. F. (1999). On the interface between personality and social psychology. In L. A. Pervin, \& O. P. John (Eds.), Handbook of personality: Theory and research (second edition, pp. 367377). New York: Guilford.

Baumeister, R. F., \& Leary, M. R. (1995). The need to belong: Desire for interpersonal attachments as a fundamental human motivation. Psychological Bulletin, 117, 497-529.

Baumeister, R. F., Vohs, K. D., \& Funder, D. C. (2007). Psychology as the science of self-reports and finger movements: Whatever happened to actual behavior? Perspectives on Psychological Science, 2, 396-403.

Baumert, A., \& Schmitt, M. (2009). Justice sensitive interpretations of ambiguous situations. Australian Journal of Psychology, 61, $6-12$.

Beilock, S. L., Gunderson, E. A., Ramirez, G., \& Levine, S. C. (2010). Female teachers' math anxiety affects girls' math achievement. Proceedings of the National Academy of Sciences, 107, 1860-1863.

Berry, B., \& Stewart, G. L. (1997). Composition, process, and performance in self-managed groups: The role of personality. Journal of Applied Psychology, 82, 62-78.

Berscheid, E., \& Regan, P. (2005). The psychology of interpersonal relationships. Upper Saddle River, NJ: Pearson Education.

Berscheid, E., Snyder, M., \& Omoto, A. M. (2004). Measuring closeness: The Relationship Closeness Inventory (RCI) revisited. In D. J. Mashek, \& A. P. Aron (Eds.), Handbook of closeness and intimacy (pp. 81-101). Mahwah, NJ: Lawrence Erlbaum Associates Publishers.

Borkenau, P., \& Liebler, A. (1992). Trait inferences: Sources of validity at zero acquaintance. Journal of Personality and Social Psychology, 62, 645-657.

Branje, S. J. T., van Lieshout, C. F. M., \& van Aken, M. A. G. (2004). Relations between big five personality characteristics and perceived support in adolescents' families. Journal of Personality and Social Psychology, 86, 615-628.

Branje, S. J. T., van Lieshout, C. F. M., \& van Aken, M. A. G. (2005). Relations between Agreeableness and perceived support in family relationships: why nice people are not always supportive. International Journal of Behavioral Development, 29, 120-128.

Bronfenbrenner, U., Harding, J., \& Gallwey, M. (1958). The measurement of skill in social perception. In D. C. McClelland, A. L. Baldwin, U. Bronfenbrenner, \& F. L. Strodtbeck (Eds.), Talent and society (pp. 29-111). Princeton, NJ: Van Nostrand.

Brown, S. L., \& Brown, R. M. (2006). Selective Investment Theory: Recasting the functional significance of close relationships. Psychological Inquiry, 17, 1-29.

Brown, R. P., \& Josephs, R. A. (1999). A burden of proof: Stereotype relevance and gender differences in math performance. Journal of Personality and Social Psychology, 76, 246-257.

Brunswik, E. (1956). Perception and the representative design of experiments. Berkeley, CA: University of California Press.

Buss, D. M., \& Shackelford, T. K. (1997). Susceptibility to infidelity in the first year of marriage. Journal of Research in Personality, 31, 193-221.

Byrne, D. (1961). Interpersonal attraction and attitude similarity. Journal of Abnormal and Social Psychology, 62, 713-715.

Campbell, W. K. (1999). Narcissism and romantic attraction. Journal of Personality and Social Psychology, 77, 1254-1270.

Campbell, W. K., \& Foster, C. A. (2002). Narcissism and commitment in romantic relationships: An investment model analysis. Personality and Social Psychology Bulletin, 28, 484495.

Caprara, G. V., Steca, P., Cervone, D., \& Artistico, D. (2003). The contribution of self-efficacy beliefs to dispositional shyness: On social-cognitive systems and the development of personality dispositions. Journal of Personality, 71, 943-970.

Caspi, A. (1998). Personality development across the life course. In W. Damon, \& N. Eisenberg (Eds.), Handbook of child psychology: Social, emotional and personality development (volume 3, pp. 311-388). New York: Wiley.

Cervone, D., \& Shoda, Y. (1999). The coherence of personality. New York, NY: Guilford Press.

Chen, X. Y., Wang, L., \& Wang, Z. Y. (2009). Shyness-sensitivity and social, scool, and psychological adjustment in rural migrant and urban children in China. Child Development, 80, 1499-1513.

Christensen, P. N., \& Kashy, D. A. (1998). Perceptions of and by lonely people in initial social interaction. Personality and Social Psychology Bulletin, 24, 322-329. 
Cialdini, R. B. (2009). We have to break up. Perspectives on Psychological Science, 4, 5-6.

Cooper, M. L. (Ed.). (2002). Personaliy and close relationships. Journal of Personality 70(6) [Special issue].

Cooper, M. L., \& Sheldon, M. S. (2002). Seventy years of research on personality and close relationships: Substantive and methodological trends over time. Journal of Personality, 70, 783 812.

Cuperman, R., \& Ickes, W. (2009). Big Five predictors of behavior and perceptions in initial dyadic interactions: Personality similarity helps extraverts and introverts, but hurts "disagreeables". Journal of Personality and Social Psychology, 97, 667684.

Denissen, J. J. A., Penke, L., Schmitt, D. P., \& van Aken, M. A. G. (2008). Self-esteem reactions to social interactions: Evidence for sociometer mechanisms across days, people, and nations. Journal of Personality and Social Psychology, 95, 181-196.

Denissen, J. J. A., Schönbrodt, F. D., van Zalk, M., Meeus, W., \& van Aken, M. (2011). Antecedents and consequences of peerrated intelligence. European Journal of Personality.

Denissen, J. J. A., van Aken, M. A. G., \& Dubas, J. S. (2009). It takes two to tango: How parents' and adolescents' personalities link to the quality of their mutual relationship. Developmental Psychology, 45, 928-941.

DePaulo, B. M., Lindsay, J. J., Malone, B. E., Muhlenbruck, L., Charlton, K., \& Cooper, H. (2003). Cues to deception. Psychological Bulletin, 129, 74-118.

Donnellan, M. B., Larsen-Rife, D., \& Conger, R. D. (2005). Personality, family history, and competence in early adult romantic relationships. Journal of Personality and Social Psychology, 88, 562-576.

Eaton, L. G., \& Funder, D. C. (2003). The creation and consequences of the social world: An interactional analysis of extraversion. European Journal of Personality, 17, 375-395.

Ellison, P. T. \& Gray P. B. (Eds.). (2009). Endocrinology of social relationships. Cambridge, MA: Harvard University Press.

Endler, N. S., \& Hunt, J. M. (1966). Sources of behavioral variance as measured by the S-R Inventory of Anxiousness. Psychological Bulletin, 65, 336-346.

Evans, J. St. B. T. (2008). Dual-processing accounts of reasoning, judgment, and social cognition. Annual Review of Psychology, 59, 255-278.

Fiske, A. P. (1992). The four elementary forms of sociality: Framework for a unified theory of social relations. Psychological Review, 99, 689-723.

Foster, J. D., Shrira, I., \& Campbell, W. K. (2006). Theoretical models of narcissism, sexuality, and relationship commitment. Journal of Social and Personal Relationships, 23, 367-386.

Fraley, C., \& Roberts, B. W. (2005). Patterns of continuity: A dynamic model for conceptualizing the stability of individual differences in psychological constructs across the life course. Psychological Review, 112, 60-74.

Fraley, R. C., \& Shaver, P. R. (1998). Airport separations: A naturalistic study of adult attachment dynamics in separating couples. Journal of Personality and Social Psychology, 75, 1198 1212.

Funder, D. C. (1991). Global traits: A neo-Allportian approach to personality. Psychological Science, 2, 31-39.

Funder, D. C. (1999). Personality judgment: A realistic approach to person perception. San Diego, CA: Academic Press.

Funder, D. C. (2001). Personality. Personality. Annual Review of Psychology, 52, 197-221.

Funder, D. C. (2009). Naive and obvious questions. Perspectives on Psychological Science, 4, 340-344.

Furr, R. M. (2009). Personality psychology as a truly behavioural science. European Journal of Personality, 23, 369-401.

Gleason, K. A., Jensen-Campbell, L. A., \& Ickes, W. (2009). The role of empathic accuracy in adolescents' peer relations and adjustment. Personality and Social Psychology Bulletin, 35, $997-$ 1011.
Gosling, S. D., Ko, S. J., Mannarelli, T., \& Morris, M. E. (2002). A room with a cue: Personality judgments based on offices and bedrooms. Journal of Personality and Social Psychology, 82, 379-398.

Gottman, J. M. (1994). What predicts divorce? Hillsdale: Erlbaum.

Gottman, J. M., Coan, J., Carrere, S., \& Swanson, C. (1998). Predicting marital happiness and stability from newlywed interactions. Journal of Marriage and the Family, 60, 5-22.

Grammer, K., Kruck, K. B., \& Magnusson, M. S. (1998). The courtship dance: Patterns of nonverbal synchronization in opposite-sex encounters. Journal of Nonverbal Behavior, 22, 3-29.

Hall, J., Coats, E., \& LeBeau, L. (2005). Nonverbal behavior and the vertical dimension of social relations: A meta-analysis. Psychological Bulletin, 131, 898-924.

Hartung, F.-M., \& Renner, B. (2011). Social curiosity and interpersonal perception: A judge $\times$ trait interaction. Manuscript submitted for publication.

Hinde, R. (1979). Towards understanding relationships. London: Academic Press.

Hofstee, W. K. B. (1994). Who should own the definition of personality? European Journal of Personality, 8, 149-162.

Hogan, R., \& Roberts, B. W. (2000). A socioanalytic perspective on person/environment interaction. In W. B. Walsh, \& K. H. Craik, \& R. H. Price (Eds.), New directions in personenvironment psychology (pp. 1-24). Hillsdale, NJ: Lawrence Erlbaum.

Holmes, J. G. (2002). Interpersonal expectations as the building blocks of social cognition: An interdependence theory perspective. Personal Relationships, 9, 1-26.

James, W. (1981). Principles of psychology: Volumes 1 and 2. Cambridge, MA: Harvard University Press (Originally published in 1890).

John, O. P., Naumann, L. P., \& Soto, C. J. (2008). Paradigm shift to the integrative Big Five trait taxonomy: History, measurement, and conceptual issues. In O. P. John, \& R. W. Robins, \& L. A. Pervin (Eds.), Handbook of personality: Theory and research (pp. 114-158). New York: Guilford.

Jussim, L., \& Harber, K. D. (2005). Teacher expectations and selffulfilling prophecies: Knows and unknowns, resolved and unresolved controversies. Personality and Social Psychology Review, 9, 131-155.

Karney, B., \& Bradbury, T. N. (1997). Neuroticism, marital interaction, and the trajectory of marital satisfaction. Journal of Personality and Social Psychology, 72, 1075-1092.

Kelley, H. H., Berscheid, E., Christensen, A., Harvey, J. H., Huston, T. L., Levinger, G., et al. (1983). Close relationships. New York: Freeman.

Kenny, D. A. (1994). Interpersonal perception: A social relations analysis. New York: Guilford Press.

Kenny, D. A., Kashy, D. A., \& Cook, W. L. (2006). Dyadic data analysis. New York: Guilford.

Kenny, D. A., West, T. V., Cillessen, A. H. N., Coie, J. D., Hubbard, J. A., \& Schwartz, D. (2007). Accuracy in judgments of aggressiveness. Personality and Social Psychology Bulletin, 33, $1225-1236$

Knee, C. R. (1998). Implicit theories of relationships: Assessment and prediction of romantic relationship initiation, coping, and longevity. Journal of Personality and Social Psychology, 74, 360-370.

Knee, C. R., Lonsbary, C., Canevello, A., \& Patrick, H. (2005). Selfdetermination and conflict in romantic relationships. Journal of Personality and Social Psychology, 89, 997-1009.

Kniffin, K. M., \& Wilson, D. S. (2004). The effect of nonphysical traits on the perception of physical attractiveness: Three naturalistic studies. Evolution and Human Behavior, 25, 88101.

Kolar, D. W., Funder, D. C., \& Colvin, C. R. (1996). Comparing the accuracy of personality judgments by the self and knowledgeable others. Journal of Personality, 64, 311-337. 
Krueger, J. I. (2009). A componential model of situation effects, person effects, and situation-by-person interaction effects on social behavior. Journal of Research in Personality, 43, $127-136$

Lang, F. R., Wagner, J., \& Neyer, F. J. (2009). Interpersonal functioning across the lifespan: Two principles of relationship regulation. Advances in Life Course Research, 14, 40-51.

Leary, M. R., \& Baumeister, R. F. (2000). The nature and function of self-esteem: Sociometer theory. Advances in Experimental Social Psychology, 32, 1-62.

Lehnart, J., Neyer, F. J., \& Eccles, J. (2010). Long-term effects of social investment: The case of partnering in young adulthood. Journal of Personality, 78, 639-669.

Levinger, G. (1994). Figure versus ground: Micro- and macroperspectives on the social psychology of personal relationships. In R. Erber, \& R. Gilmour (Eds.), Theoretical frameworks for personal relationships (pp. 1-28). Hillsdale, NJ: Erlbaum.

Malloy, T. E., \& Kenny, D. A. (1986). The Social Relations Model: An integrative methodology for personality research. Journal of Personality, 54, 199-225.

McAdams, D. P. (2008). Personal narratives and the life story. In O. John, R. Robins, \& L. Pervin (Eds.), Handbook of personality: Theory and research (third edition, pp. 241-261). New York: Guilford Press.

McAdams, D. P., \& Pals, J. L. (2006). A new big five: Fundamental principles for an integrative science of personality. American Psychologist, 61, 204-217.

McCrae, R. R., \& Costa, P. T. (2008). The five-factor theory of personality. In O. P. John, R. W. Robins, \& L. A. Pervin (Eds.), Handbook of personality: Theory and research (pp. 159-181). New York: Guilford.

Mercer, S. H., \& DeRosier, M. E. (2008). Teacher preference, peer rejection, and student aggression: A prospective study of transactional influence and independent contributions to emotional adjustment and grades. Journal of School Psychology, 46, 661-685.

Mischel, W. (1973). Toward a cognitive social learning reconceptualization of personality. Psychological Review, 80, 252 283.

Mischel, W., \& Shoda, Y. (1995). A cognitive-affective system theory of personality: Reconceptualizing situations, dispositions, dynamics, and invariance in personality structure. Psychological Review, 102, 246-268.

Morf, C. C., \& Rhodewalt, F. (1993). Narcissism and self-evaluation maintenance: Explorations in object relations. Personality and Social Psychology Bulletin, 19, 668-676.

Morf, C. C., \& Rhodewalt, F. (2001). Unraveling the paradoxes of narcissism: A dynamic self-regulatory processing model. Psychological Inquiry, 12, 177-196.

Neyer, F. J., \& Asendorpf, J. B. (2001). Personality relationship transaction in young adulthood. Journal of Personality and Social Psychology, 81, 1190-1204.

Neyer, F. J., \& Lang, F. R. (2003). Blood is thicker than water: Kinship orientation across adulthood. Journal of Personality and Social Psychology, 84, 310-321.

Neyer, F. J., \& Lehnart, J. (2007). Relationships matter in personality development: Evidence from an 8-year longitudinal study across young adulthood. Journal of Personality, 75, 535568.

Neyer, F. J., Wrzus, C., Wagner, J., \& Lang, F. R. (in press) Principles of relationship differentiation. European Psychologist.

Nosek, B. A., Smyth, F. L., Sriram, N., Lindner, N. M., Devos, T., Ayala, A., et al. (2009). National differences in gender-science stereotypes predict national sex differences in science and math achievement. Proceedings of the National Academy of Sciences, 106, 10593-10597.

Otway, L. J., \& Vignoles, V. L. (2006). Narcissism and childhood recollections: A quantitative test of psychoanalytic predictions. Personality and Social Psychology Bulletin, 32, 104-116.
Paulhus, D. L. (1998). Interpersonal and intrapsychic adaptiveness of trait self-enhancement: A mixed blessing. Journal of Personality and Social Psychology, 74, 1197-1208.

Penke, L. (2009). An ethological perspective on how to define and study behaviour. A commentary on Furr. European Journal of Personality, 23, 421-423.

Penke, L., Denissen, J. J. A., \& Miller, G. F. (2007). The evolutionary genetics of personality (target article). European Journal of Personality, 21, 549-587.

Penke, L., Todd, P. M., Lenton, A., \& Fasolo, B. (2007). How selfassessments can guide human mating decisions. In G. Geher, \& G. F. Miller (Hrsg.) Mating intelligence: Sex, relationships, and the mind's reproductive system (pp. 37-75). Mahwah, NJ: Lawrence Erlbaum.

Robbins, S. B., Lauver, K., Davis, D., Langley, R., \& Carlstrom, A. (2004). Do psychosocial and study skill factors predict college outcomes? A meta analysis. Psychological Bulletin, 130, 261288.

Robert, C., \& Cheung, Y. H. (2010). An examination of the relationship between conscientiousness and group performance on a creative task. Journal of Research in Personality, 44, 222231.

Roberts, B. W., \& Bogg, T. (2004). A longitudinal study of the relationships between conscientiousness and the social-environmental factors and substance-use behaviors that influence health. Journal of Personality, 72, 325-353.

Roberts, B. W., \& Chapman, C. (2000). Change in dispositional well-being and its relation to role quality: A 30 -year longitudinal study. Journal of Research in Personality, 34, 26-41.

Roberts, B. W., \& DelVecchio, W. F. (2000). The rank-order consistency of personality from childhood to old age: A quantitative review of longitudinal studies. Psychological Bulletin, 126, 3-25.

Roberts, B. W., Walton, K. E., \& Viechtbauer, W. (2006). Patterns of mean-level change in personality traits across the life course: A meta-analysis of longitudinal studies. Psychological Bulletin, $132,1-25$.

Roberts, B. W., \& Wood, D. (2006). Personality development in the context of the neosocioanalytic model of personality. In D. K. Mroczek, \& T. D. Little (Eds.), Handbook of personality development (pp. 11-39). Mahwah, NJ: Erlbaum.

Roberts, B. W., Wood, D., \& Smith, J. L. (2005). Evaluating five factor theory and social investment perspectives on personality trait development. Journal of Research in Personality, 39, 166184.

Robins, R. W., Caspi, A., \& Moffitt, T. E. (2002). It's not just who you're with, it's who you are: Personality and relationship experiences across multiple relationships. Journal of Personality, 70, 925-964.

Rosenthal, R., \& Jacobson, L. (1992). Pygmalion in the classroom (expanded edition). New York: Irvington.

Rubin, K. H. Asendorpf J. B. (Eds.). (1993). Social withdrawal, inhibition and shyness in childhood. Hillsdale, NJ: Erlbaum.

Rusting, C. L. (1998). Personality, mood, and cognitive processing of emotional information: Three conceptual frameworks. Psychological Bulletin, 124, 165-196.

Schöder-Abé, M., \& Schütz, A. (2011). Walking in each other's shoes: Perspective taking mediates effects of emotional intelligence on relationship quality. European Journal of Personality.

Schultz, L. T., \& Heimberg, R. G. (2008). Attentional focus in social anxiety disorder: Potential for interactive processes. Clinical Psychology Review, 28, 1206-1221.

Scollon, C. N., \& Diener, E. (2006). Love, work, and changes in extraversion and neuroticism over time. Journal of Personality and Social Psychology, 91, 1152-1165.

Selfhout, M. H. W., Burk, W. J., Denissen, J. J. A., Branje, S. J. T., van Aken, M. A. G., \& Meeus, W. H. J. (2010). Emerging late adolescent friendship networks and Big Five personality traits: A social network approach. Journal of Personality, 78, 509-538. 
Shaver, P. R., \& Mikulincer, M. (2006). Attachment theory, individual psychodynamics, and relationship functioning. In A. L. Vangelisti, \& D. Perlman (Eds.), The Cambridge handbook of personal relationships (pp. 251-271). New York: Cambridge University Press.

Simpson, J. A., Orina, M., \& Ickes, W. (2003). When accuracy hurts, and when it helps: A test of the empathic accuracy model in marital interactions. Journal of Personality and Social Psychology, 85, 881-893.

Simpson, J. A., Collins, W. A., Tran, S., \& Haydon, K. C. (2007). Attachment and the experience and expression of emotions in romantic relationships: A developmental perspective. Journal of Personality and Social Psychology, 92, 355-367.

Smith, E. R., \& DeCoster, J. (2000). Dual-process models in social and cognitive psychology: Conceptual integration and links to underlying memory systems. Personality and Social Psychology Review, 4, 108-131.

Snyder, M., \& Ickes, W. (1985). Personality and social behavior. In G. Lindzey, \& E. Aronson (Eds.), Handbook of social psychology (volume II, third edition). New York: Random House.

Snyder, M., \& Swann, W. B., Jr. (1978). Behavioral confirmation in social interaction: From social perception to social reality. Journal of Experimental Social Psychology, 14, 148-162.

Srivastava, S., Angelo, K. M., \& Vallereux, S. R. (2008). Extraversion and positive affect: A day reconstruction study of person-environment transactions. Journal of Research in Personality, 42, 1613-1618.

Srivastava, S., John, O. P., Gosling, S. D., \& Potter, J. (2003). Development of personality in early and middle adulthood: Set like plaster or persistent change? Journal of Personality and Social Psychology, 84, 1041-1053.

Srivastava, S., McGonigal, K. M., Richards, J. M., Butler, E. A., \& Gross, J. J. (2006). Optimism in close relationships: How seeing things in a positive light makes them so. Journal of Personality and Social Psychology, 91, 143-153.

Strack, F., \& Deutsch, R. (2004). Reflective and impulsive determinants of social behavior. Personality and Social Psychology Review, 8, 220-247.

Swann, W. B., Jr., \& Bosson, J. K. (2008). Identity negotiation: A theory of self and social interaction. In O. P. John, R. W. Robins,
\& L. A. Pervin (Eds.), Handbook of personality: theory and research (pp. 448-471). New York: Guilford.

Tay, C., Ang, S., \& Van Dyne, L. (2006). Personality, biographical characteristics, and job interview success: A longitudinal study of the mediating effects of interviewing self-efficacy and the moderating effects of internal locus of causality. Journal of Applied Psychology, 91, 446-454.

Uller, T. (2003). Human mate choice and the wedding ring effect Are married men more attractive? Human Nature, 14, 267-276.

van Aken, M. A. G., Denissen, J. J. A., Branje, S. J. T., Dubas, J. S., \& Goosens, L. (2006). Midlife concerns and short-term personality change in middle adulthood. European Journal of Personality, 20, 497-513.

Vazire, S. (2010). Who knows what about a person? The Self-Other Knowledge Asymmetry (SOKA) Model. Journal of Personality and Social Psychology, 98, 281-300.

Vazire, S., \& Funder, D. C. (2006). Impulsivity and the selfdefeating behavior of narcissists. Personality and Social Psychology Review, 10, 154-165.

Vazire, S., \& Mehl, M. R. (2008). Knowing me, knowing you: The accuracy and unique predictive validity of self-ratings and otherratings of daily behavior. Journal of Personality and Social Psychology, 95, 1202-1216.

Vohs, K. D., \& Finkel, E. J. (2006). Self and relationships. Connecting intrapersonal and interpersonal processes. New York: Guilford Press.

Vollmann, M., Antoniw, K., Hartung, F.-M., \& Renner, B. (2011). Social support as mediator of the stress buffering effect of optimism: The importance of differentiating the recipients' and providers' perspective. European Journal of Personality.

Vollrath, M., Krahé, B., \& Hampson, S. (2004). Personality and social relations [Special issue]. European Journal of Personality, 18(4).

Wood, J. V., Tesser, A., \& Holmes, J. G. (2008). The self and social relationships. New York: Psychology Press.

Wrzus, C., Wagner, J., Baumert, A., Lang, F. R., \& Neyer, F. J. (2011). Prosocial personality and reciprocity of support in adult parent-child relationships through the lens of social relations analyses. European Journal of Personality.

Zayas, V., Shoda, Y., \& Ayduk, O. N. (2002). Personality in context: An interpersonal systems perspective. Journal of Personality, 70, 851-900. 